\title{
LongRunMIP \\ Motivation and Design for a Large Collection of Millennial-Length AOGCM Simulations
}

\author{
Maria Rugenstein, Jonah Bloch-Johnson, Ayako Abe-Ouchi, Timothy Andrews, \\ Urs Beyerle, long Cao, Tarun Chadha, Gokhan Danabasoglu, Jean-Louis Dufresne, \\ Lei Duan, Marie-Alice Foujols, Thomas Frölicher, Olivier Geoffroy, Jonathan Gregory, \\ Reto Knutti, Chao li, Alice Marzocchi, Thorsten Mauritsen, Matthew Menary, \\ Elisabeth Moyer, Larissa Nazarenko, David Paynter, David Saint-Martin, \\ Gavin A. Schmidt, Akitomo Yamamoto, and Shuting Yang
}

LongRunMIP is the first collection of millennial-length simulations of complex coupled climate models and enables investigations of how these models equilibrate in response to radiative perturbations.

M illennial-length climate model simulations are necessary to understand the equilibration that occurs in response to external forcings, as well as the relationship between transient and equilibrated states. Unforced millennial-length simulations are useful as well, as they allow us to consider long-term internal variability and to analyze shorter-term variability with increased statistical certainty. Reasons to study these long time scales include the following:

- To better understand long-term climate dynamics. Outstanding issues include the time scales of ocean circulation response (e.g., Jansen et al. 2018; Rind et al. 2018), continental drying trends (e.g., Sniderman et al. 2019) or sea level rise (e.g., Bilbao et al. 2015; Rugenstein et al. 2016c).

- To help predict the impacts of twentieth- and twenty-first-century emissions on century time scales, such as ice sheet stability, deep ocean warming, or polar amplification (e.g., Frölicher and Joos 2010; Clark et al. 2016; Mauritsen and Pincus 2017), which are rarely explicitly simulated using a fully coupled climate model.

- To more accurately estimate equilibrium climate sensitivity (ECS), which is the equilibrium response of the surface air temperature to a doubling of $\mathrm{CO}_{2}$ due to the "fast" feedbacks such as water vapor, lapse rate, clouds, and sea ice but excluding Earth system feedbacks such as changes in the carbon cycle, ice sheets, or vegetation. While ECS has long been a focus of scientific inquiry, substantial uncertainty remains as to its value (e.g., Charney et al. 1979; Knutti et al. 2017).

- To understand the relationship between the transient response of the climate and its equilibration. Since radiative feedbacks can depend on the evolution of the spatial pattern of warming (e.g., Senior and Mitchell 2000; Winton et al. 2010; Armour et al. 2013; Andrews et al. 2015; Andrews and Webb 2018) and on the background temperature (e.g., Colman and McAvaney 2009; Caballero and Huber 2013; Block and Mauritsen 
2013; Meraner et al. 2013; Bloch-Johnson et al. 2015), a constant effective sensitivity of the climate is an inadequate assumption. Several methods have been proposed to predict the equilibrium response from transient simulations given a changing global feedback (Held et al. 2010; Winton et al. 2010; Armour et al. 2013; Geoffroy et al. 2013a,b; Frölicher et al. 2014; Proistosescu and Huybers 2017; Saint-Martin et al. 2019), but only fully equilibrated climate model simulations can serve to test how well these methods predict equilibrium conditions.

- To test theories for the relationship between feedbacks at different time scales (Gregory et al. 2015, 2016; Zhou et al. 2016; Rugenstein et al. 2016a; Armour 2017; Proistosescu and Huybers 2017; Ceppi and Gregory 2017; Andrews and Webb 2018; Andrews et al.2018) and to quantify the influence of slow, centennial-scale modes on the temperature evolution of the last century (Armour 2017; Proistosescu and Huybers 2017).

- To understand the relevance, time scales, and magnitude of the energy imbalances and drifts exhibited by climate models (e.g., Hobbs et al. 2016), with the potential application of decreasing the spinup time needed to run these models.

- To understand the relationship between the forced response and internal variability. This relationship is currently studied using the time frame of one or two centuries, which is not enough to robustly quantify the internal variability under consideration (e.g., Maher et al. 2018; Lutsko and Takahashi 2018), millennial time scales with varying forcings (e.g., Köhler et al. 2017; Khon et al. 2018; Rehfeld et al. 2018) or by using expensive large ensemble simulations on decadal to centennial time scales (e.g., Deser et al. 2012; Rodgers et al. 2015; Maher et al. 2019). Millennial-length simulations allow us to differentiate the transient response from the equilibrated forced response, even for quantities with large internal variability, such as precipitation, droughts, or El Niño-Southern Oscillation (ENSO), and also the significance of a change in internal variability in a transient simulation relative to the control simulation (e.g., Brown et al. 2017).

- To compare climate model responses and paleo proxies, for example, of surface or deep ocean temperatures or hydrological conditions on land in order to provide an independent way of testing climate models (Gebbie and Huybers 2019; Burls and Fedorov 2017; Scheff et al. 2017).

With LongRunMIP, we aim to advance knowledge in the above mentioned areas, fill a gap in the CMIP protocols (Taylor et al. 2012; Eyring et al. 2016), and collect published data in one location for easy public access.

The goals of LongRunMIP are as follows:

1) to continuously gather existing millennial-length simulations (both published and unpublished),
AFFILIATIONS: RUgENSTEIN-Institute for Atmospheric and Climate Science, ETH Zurich, Zurich, Switzerland, and Max Planck Institute for Meteorology, Hamburg, Germany; BLOCH-JOHNsoN-National Centre for Atmospheric Science, University of Reading, Reading, United Kingdom; ABE-OUCHI-Atmosphere and Ocean Research Institute, The University of Tokyo, Tokyo, Japan; ANDREWs-Met Office Hadley Centre, Exeter, United Kingdom; BeYerLe AND KNUTtI-Institute for Atmospheric and Climate Science, ETH Zurich, Zurich, Switzerland; CAO AND DUAN-School of Earth Sciences, Zhejiang University, Hang Zhou, Zhejiang, China; CHADHA-IT Service Research Informatics, ETH Zurich, Zurich, Switzerland; DANABASOGLU—National Center for Atmospheric Research, Boulder, Colorado; Dufresne-Centre National de la Recherche Scientifique, Sorbonne Université, ENS, Ecole Polytechnique, Paris, France; Foujols_-Institut Pierre-Simon-Laplace, Sorbonne Université/CNRS, Paris, France; FRÖLICHER-Climate and Environmental Physics, Physics Institute, and Oeschger Centre for Climate Change Research, University of Bern, Bern, Switzerland; Geoffroy and SaINT-Martin-CNRM, Université de Toulouse, Météo-France, CNRS, Toulouse, France; GREGORY - National Centre for Atmospheric Science, University of Reading, Reading, and Met Office Hadley Centre, Exeter, United Kingdom; LI-Max
Planck Institute for Meteorology, Hamburg, Germany; MaRZOCCHINational Oceanography Centre, Southampton, United Kingdom; MaURITSEN-Stockholm University, Stockholm, Sweden; MenarYLaboratoire d'Océanographie et du Climat, Sorbonne Université, Paris, France; MOYER-Department of the Geophysical Sciences, University of Chicago, Chicago, Illinois; NAZARENKO AND SCHMIDTNASA Goddard Institute for Space Studies, New York, New York; PAYNTER-Geophysical Fluid Dynamics Laboratory, Princeton, New Jersey; Yамамото-Japan Agency for Marine-Earth Science and Technology, Yokohama, Japan; YANG_Danish Meteorological Institute, Copenhagen, Denmark CORRESPONDING AUTHOR: Maria Rugenstein, maria.rugenstein@mpimet.mpg.de

The abstract for this article can be found in this issue, following the table of contents.

DOI:10.1I75/BAMS-D-19-0068.I

A supplement to this article is available online (10.II75/BAMS-D-19-0068.2)

In final form 5 August 2019

(C)2019 American Meteorological Society

For information regarding reuse of this content and general copyright

information, consult the AMS Copyright Policy. 
2) to standardize the collected data (e.g., using the same units and sign conventions),

3) to make the data publicly available and easily accessible, and

4) to foster an interdisciplinary community of users working on millennial-length problems, with experts on oceanography, atmospheric dynamics, energy balance modeling, ice sheet modeling, and paleoclimatology.

The objectives of this paper are as follows:

1) to motivate the data collection strategy,

2) to specify the requirements for LongRunMIP contributors,

3) to give an overview of currently submitted simulations and models,

4) to give a sample of some initial analysis on these simulations,

5) to show how LongRunMIP relates to the existing literature on millennial-length simulations, and

6) to discuss the limitations and opportunities of LongRunMIP.

\section{EXPERIMENTAL DESIGN AND DATA} COLLECTION STRATEGY. LongRunMIP is the first and largest compilation of millennial-length simulations of complex climate models to date, where a "complex climate model" is understood to include an atmospheric, sea ice, land, and full-depth ocean component, that is, atmosphere-ocean general circulation models (AOGCMs) with a dynamic atmosphere and ocean, as opposed to Earth system models of intermediate complexity (EMIC), which are often used to study millennial-length questions in climate science (e.g., Zickfeld et al. 2013; Levermann et al. 2013). These model simulations include the "fast" feedbacks, such as changes in water vapor, lapse rate, sea ice, and clouds (Charney et al. 1979), but does not include "slow" feedbacks, such as changes in the ice sheets. Vegetation is treated differently in the models (see "Minimal, optimal, and current contributions" section). In the "Discussion and outlook" section we discuss the implications and limitations of our approach.

Our goal is to collect as many simulations from as many independent models as possible, while keeping the archive and data sharing manageable. Consequently, we keep our requirements for contributions low.

Simulations and variables. A step increase in atmospheric $\mathrm{CO}_{2}$ concentrations (in the following called "step forcing") is one of the simplest experiments for studying a model's response to forcing and is a benchmark simulation in CMIP3, CMIP5, and CMIP6 (Meehl et al. 2007; Taylor et al. 2011; Eyring et al. 2016). More realistic, gradual forcing scenarios have been shown to be representable by the step-forcing scenarios and exhibit feedbacks that correlate with those computed from step-forcing simulations (Good et al. 2013, 2015; Geoffroy and Saint-Martin 2014; Colman and Hanson 2016). The CMIP3 protocol required a step forcing of doubling atmospheric $\mathrm{CO}_{2}$ (here referred to as abrupt2x) above preindustrial levels in a slab (i.e., nondynamical) ocean, which for decades has been used to define ECS (e.g., Charney et al. 1979; Boer and Yu 2003c; Danabasoglu and Gent 2009). The integration time scale of these model setups are a couple of decades. However, a quadrupling of $\mathrm{CO}_{2}$ (here referred to as abrupt $4 \mathrm{x}$ ) above preindustrial levels has a better ratio of forced signal to internal variability. Because the forced response was assumed to scale linearly with increased forcing, the CMIP5 protocol requested an abrupt quadrupling of $\mathrm{CO}_{2}$, now in a fully coupled model with a dynamical ocean, requiring longer integration time scales. The CMIP6 protocol again requests abrupt $\mathrm{CO}_{2}$ quadrupling experiments, but encourages also the submission of abrupt $\mathrm{CO}_{2}$ doublings, to study the relation between different forcing levels (Eyring et al. 2016; Good et al. 2016). CMIP5 and CMIP6 protocols require the submission of 150 years of model output. A representative response of surface temperature anomalies and top of the atmosphere (TOA) radiative imbalance to an abrupt4x scenario is shown in Fig. 1. All anomalies mentioned in this paper are computed as the difference of the experiment from the average of the control simulation. After the 150 years of CMIP protocol length (blue shading) and after 1,000 years (the minimum contribution to LongRunMIP, light red shading), the surface temperature response of the exemplary model shown here has reached $75 \%$ and $88 \%$ of its final value, respectively, while the TOA radiation has equilibrated $85 \%$ and $93 \%$ of the forcing, respectively ( $7.6 \mathrm{~W} \mathrm{~m}^{-2}$ for this model). Thus, the final equilibration is a CPU-intensive exercise; the model shown here needs 4,000 years to balance the final $0.5 \mathrm{~W} \mathrm{~m}^{-2}$ (dark red shading).

The set of variables we collect is motivated by the interest of the LongRunMIP contributors and organizers in ECS, temperature- and time-dependent feedbacks, and deep ocean warming. Table 1 lists the variable names, units, and temporal and spatial resolution of the requested variables. The naming and sign 


\section{Experimental setup}
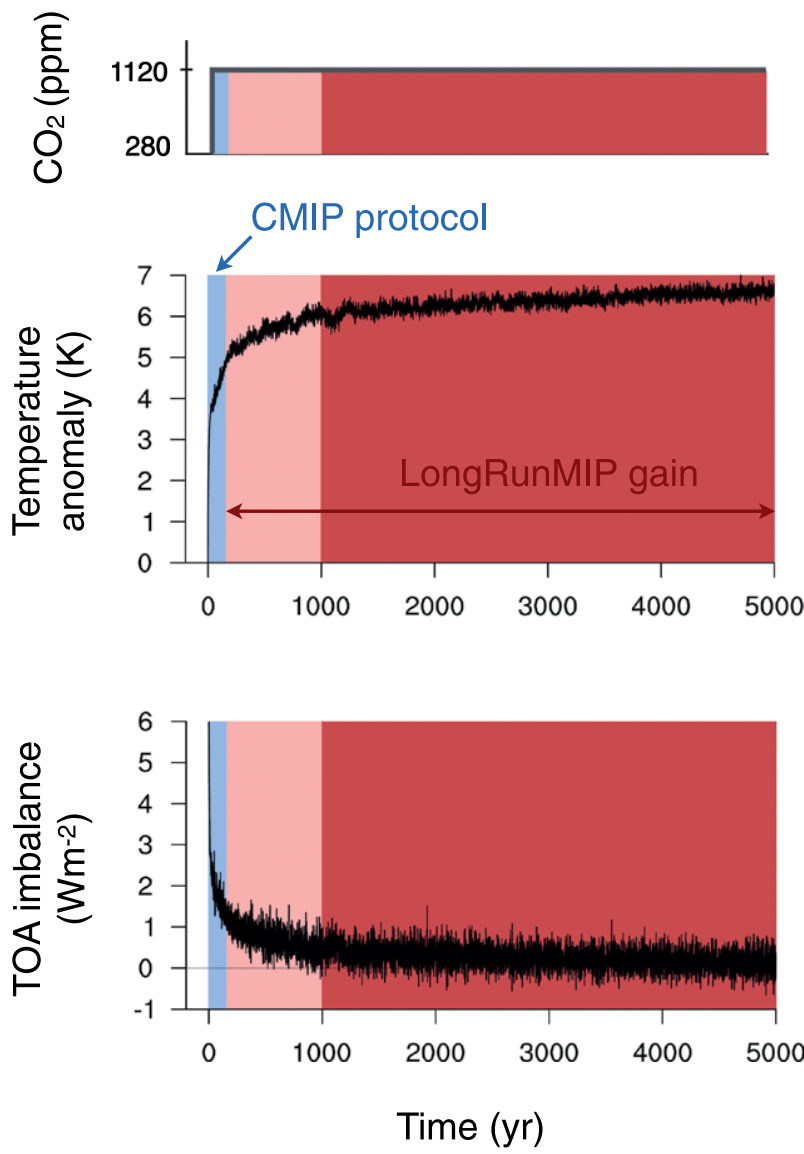

Fig. I. Global- and annual-mean surface air temperature (tas in Table I) anomaly and TOA radiative imbalance (computed as rsdt - rlut - rsut; see Table I) to a step forcing of quadrupling $\mathrm{CO}_{2}$ as simulated by the model CESMI04. For CMIP5 and CMIP6, this simulation is part of the standard protocol, but only I50 simulated years are requested (blue shading). We collect simulations that extended this experiment for at least $\mathbf{8 5 0}$ years (light red shading), ideally until they are equilibrated (end of dark red shading).

conventions follow the CMIP5 protocol. ${ }^{1}$ Given the large amount of data involved, we have kept the list of requested variables short to allow as many groups as possible to participate. For the same reason, we do not request the data to be "CMORized," (i.e., written in conformance with the CMIP standards). However, we do homogenize signs, variable long names, and units, and also provide a regridded version of the fields, as well as global means.

Minimal, optimal, and current contributions. The minimal requirement to contribute to LongRunMIP are

${ }^{1}$ http://cmip-pcmdi.IInl.gov/cmip5/data_description.html

${ }^{2}$ https://pcmdi.IInl.gov/CMIP6/Guide/dataUsers.html annual fields of a single simulation of any $\mathrm{CO}_{2}$ forcing scenario that has at least 1,000 years of constant forcing, along with a control simulation of any length. The complexity of the model should be CMIP5 class and include dynamic atmosphere, ocean, and sea ice components. An optimal contribution comprises monthly fields of fully equilibrated abrupt $2 \mathrm{x}$, abrupt $4 \mathrm{x}$, and abrupt $8 \mathrm{x}$ simulations and a control simulation of several millennia.

Table 2 lists the model characteristics of the current contributions. Because the archive is assembled from experiments initiated independently for research purposes by multiple modeling groups, there is no predefined protocol like for the CMIP simulations. The models are diverse in origin and sample the CMIP5 range of models well [see discussion on model genealogy in Knutti (2010)]. Table 2 lists references for each model and publications using (parts of) the model output. Most of the current contributions to LongRunMIP are extensions of CMIP5 simulations, sometimes with updated model versions, while one model is an extension of a CMIP3 and another model an extension of a CMIP6 contributions (CCSM3 and CNRMCM61, respectively).

Many of our current contributions fall short of the optimal expectation for equilibrium, because even several millennia are insufficient for the deep ocean to equilibrate (see discussion around Fig. 4). However, a few millennia appear to be enough for the surface temperature and TOA radiative imbalance to reach a new steady state in most models (see "Sample of model output" section), and many questions can be adequately addressed with the current contributions. Our approach is to be inclusive, and to leave it to the user to determine the degree of equilibration needed for their research and to develop criteria for model selection.

Most contributions are step-forcing simulations, generally to 2 or 4 times preindustrial $\mathrm{CO}_{2}$ concentrations (in Fig. 2, abrupt $2 \mathrm{x}$ colored in yellow, abrupt $4 \mathrm{x}$ in orange, abrupt8x in dark red; abrupt $2.4 \mathrm{x}$ and abrupt $4.8 \mathrm{x}$ in dark and light pink). There are currently three exceptions: 1) Some model simulations have gradual increases in $\mathrm{CO}_{2}$ at $1 \% \mathrm{yr}^{-1}$ until doubled or quadrupled concentrations are reached, after which the concentration is kept constant (1pct2x and 1pct $4 \mathrm{x}$, light and medium red in Fig. 2). 2) One model simulates the 1850-2010 period, after which $\mathrm{CO}_{2}$ increases piecewise linearly for 90 years until reaching 2.4 times preindustrial values (CCSM3II). 3) Finally, one model simulates the historical period and then the CMIP5 extended representative concentration pathway 8.5 (including changes in $\mathrm{CH}_{4}, \mathrm{~N}_{2} \mathrm{O}, \mathrm{CFC} 11$, and $\mathrm{CFC1} 2$ in addition to $\mathrm{CO}_{2}$ ) until year 2300 after which all 
forcing agents are kept constant (RCP8.5+, violet in Fig. 2)

For the models that did not contribute a millennial-long step-forcing simulation, we collect short (typically 150 years) step-forcing simulations, generally from the CMIP5 archive. These simulations can be used to estimate the effective climate sensitivity and to relate transient and equilibrium responses (they are not mentioned in Table 2 and Fig. 2).

Most contributors were able to submit all requested variables. Some models only stored annual output, while for a few models the entire model output (including many more variables than listed in Table 1) is available. In principle, but with considerable effort, additional variables not listed in Table 1 could be requested from some or all contributors.

Some models are outliers in some sense. For example, the simulation abrupt $4 x$ of FAMOUS warms anomalously strongly (Figs. 2 and 7) due to a shortwave cloud effect that is positive throughout the simulation and longwave clear-sky effect that increases anomalously strongly (not shown; see Rugenstein et al. 2019). In principle though, such extreme behavior could represent possible characteristics of the real world (e.g., Bloch-Johnson et al. 2015; Schneider et al. 2019). Another atypical model is EC-EARTH-Parallel Ice Sheet Model (EC-EARTHPISM), which is the only model with an interactive Greenland ice sheet. This additional component and its historical and RCP8.5+ forcing scenario makes it harder to compare the simulation to other models and attribute changes to one forcing component. This model also does not equilibrate but eventually produces a negative TOA imbalance, which probably would increase if the simulation was integrated further. We encourage similar "problematic" submissions, since our focus is on understanding model behavior and the large range of model responses (discussed in "Sample of model output" section).
TABLE I. Description of collected variables. 2D means spatial resolution of latitude and longitude, except for msftmyz, where it means latitude and depth. 3D means latitude, longitude, and depth. Variable msftmyz is the sum of the eulerian, eddy bolus, and submesoscale components. For "so" and "thetao," there are also February and September values available for most models.

\begin{tabular}{|c|c|c|c|}
\hline $\begin{array}{l}\text { Short } \\
\text { name }\end{array}$ & Long name & Unit & Resolution \\
\hline hfls & Surface upward latent heat flux & $W m^{-2}$ & Monthly, 2D \\
\hline hfss & Surface upward sensible heat flux & $W m^{-2}$ & Monthly, 2D \\
\hline $\mathrm{pr}$ & Precipitation on atmospheric grid & $\mathrm{kg} \mathrm{m}^{-2} \mathrm{~s}^{-1}$ & Monthly, 2D \\
\hline psl & Sea level pressure & $\mathrm{Pa}$ & Monthly, 2D \\
\hline rlds & Surface downwelling longwave radiation & $W m^{-2}$ & Monthly, 2D \\
\hline rlus & Surface upwelling longwave radiation & $W m^{-2}$ & Monthly, 2D \\
\hline rlut & TOA outgoing longwave radiation & $W m^{-2}$ & Monthly, 2D \\
\hline rlutcs & TOA outgoing clear-sky longwave radiation & $W m^{-2}$ & Monthly, 2D \\
\hline rsds & Surface downwelling shortwave radiation & $W m^{-2}$ & Monthly, 2D \\
\hline rsdt & TOA incident shortwave radiation & $\mathrm{W} \mathrm{m}^{-2}$ & Monthly, 2D \\
\hline rsus & Surface upwelling shortwave radiation & $W m^{-2}$ & Monthly, 2D \\
\hline rsut & TOA outgoing shortwave radiation & $\mathrm{W} \mathrm{m}^{-2}$ & Monthly, 2D \\
\hline rsutcs & TOA outgoing clear-sky shortwave radiation & $W m^{-2}$ & Monthly, 2D \\
\hline tas & Near-surface air temperature & $\mathrm{K}$ & Monthly, 2D \\
\hline ts & Atmospheric surface temperature & $\mathrm{K}$ & Monthly, 2D \\
\hline sic & Sea ice area fraction & $\%$ & Monthly, 2D \\
\hline msftmyz & Meridional overturning circulation & $\mathrm{m}^{3} \mathrm{~s}^{-1}$ & Annual, 2D \\
\hline tos & Sea surface temperature & $\mathrm{K}$ & Annual, 2D \\
\hline sos & Sea surface salinity & psu & Annual, 2D \\
\hline wfo & Net water flux into seawater & $\mathrm{kg} \mathrm{m}^{-2} \mathrm{~s}^{-1}$ & Annual, 2D \\
\hline evs & Water evaporation & $\mathrm{kg} \mathrm{m}^{-2} \mathrm{~s}^{-1}$ & Annual, 2D \\
\hline Pr_ocn & Precipitation (rain and snow) on ocean grid & $\mathrm{kg} \mathrm{m}^{-2} \mathrm{~s}^{-1}$ & Annual, 2D \\
\hline tauuo & Surface downward wind stress in $x$ direction & $\mathrm{N} \mathrm{m}^{-2}$ & Annual, 2D \\
\hline auvo & Surface downward wind stress in y direction & $\mathrm{N} \mathrm{m}^{-2}$ & Annual, 2D \\
\hline so & Sea water salinity & psu & Annual, 3D \\
\hline thetao & Sea water potential temperature & $\mathrm{K}$ & Annual, 3D \\
\hline
\end{tabular}

In nine models, the vegetation is fixed to preindustrial conditions (ECHAM5, CCSM3, CCSM3II, HadCM3L, FAMOUS, MIROC32, ECEARTH, GISSE2R, CNRMCM61), while the other seven models have dynamic vegetation schemes (MPIESM11, MPIESM12, CESM104, HadGEM2, GFDLESM2M, GFDLCM3, IPSLCM5A).

SAMPLE OF MODEL OUTPUT. Imbalances in the control simulation and drift. In principle, the TOA radiative imbalance should be zero in a control simulation. Most models contributing to LongRunMIP do not lose or gain energy (Fig. 3). However, some models that are equilibrated in the sense that they 
TABLE 2. Overview of models and contributed simulations. The resolution of the atmosphere and ocean is given in number of grid points per latitude $\times$ longitude, and latitude $\times$ longitude $\times$ depth, respectively. Models are referred to by their short names throughout the manuscript. The “Minimal, optimal, and current contributions" section describes the forcing levels. References in the last column describe the models and simulations. Some simulations are published in their full length, some simulations contributed to LongRunMIP are the extensions of simulations discussed in the references, and some simulations are unpublished.

\begin{tabular}{|c|c|c|c|c|c|c|}
\hline $\begin{array}{c}\text { Model } \\
\text { (short name) }\end{array}$ & $\begin{array}{l}\text { Forcing-level } \\
\text { short name }\end{array}$ & $\begin{array}{l}\text { Length } \\
\qquad(y r)\end{array}$ & $\begin{array}{l}\text { Atmosphere } \\
\text { resolution }\end{array}$ & $\begin{array}{c}\text { Ocean } \\
\text { resolution }\end{array}$ & $\begin{array}{c}\text { Control } \\
\text { simulation } \\
(y r)\end{array}$ & $\begin{array}{l}\text { Model and simulation } \\
\text { documentation }\end{array}$ \\
\hline $\begin{array}{l}\text { CCSM3 } \\
(\mathrm{CCSM} 3)\end{array}$ & $\begin{array}{l}\text { abrupt } 2 x \\
\text { abrupt } 4 x \\
\text { abrupt8x }\end{array}$ & $\begin{array}{l}3,000 \\
2,120 \\
1,450\end{array}$ & $48 \times 96$ & $100 \times 116 \times 25$ & 1,530 & $\begin{array}{l}\text { Yeager et al. (2006) } \\
\text { Danabasoglu and Gent (2009) }\end{array}$ \\
\hline $\begin{array}{c}\text { CCSM3 } \\
(\mathrm{CCSM} 3 \mathrm{II})\end{array}$ & $\begin{array}{l}\text { abrupt } 2.4 \\
\text { abrupt } 4.8 \\
\operatorname{lin} 2.4\end{array}$ & $\begin{array}{l}3,701 \\
3,132 \\
3,990\end{array}$ & $48 \times 96$ & $100 \times 116 \times 25$ & 3,805 & $\begin{array}{l}\text { Yeager et al. (2006) } \\
\text { Castruccio et al. (2014) }\end{array}$ \\
\hline $\begin{array}{l}\text { CESM I.0.4 } \\
(\text { CESMI04) }\end{array}$ & $\begin{array}{l}\text { abrupt } 2 x \\
\text { abrupt } 4 x \\
\text { abrupt8x }\end{array}$ & $\begin{array}{l}2,500 \\
5,900 \\
5,100\end{array}$ & $96 \times 144$ & $384 \times 20 \times 60$ & $\mathrm{I}, 320$ & $\begin{array}{l}\text { Gent et al. (20II) } \\
\text { Danabasoglu et al. (20l2) } \\
\text { Rugenstein et al. (20l6c) }\end{array}$ \\
\hline $\begin{array}{l}\text { CNRM-CM6-I } \\
\text { (CNRMCM6I) }\end{array}$ & $\begin{array}{l}\text { abrupt } 2 x \\
\text { abrupt } 4 x\end{array}$ & $\begin{array}{r}750 \\
I, 850\end{array}$ & $128 \times 256$ & $180 \times 360 \times 75$ & 2,000 & $\begin{array}{l}\text { Voldoire et al. (2019) } \\
\text { Saint-Martin et al. (2019) }\end{array}$ \\
\hline $\begin{array}{c}\text { EC-EARTH-PISM } \\
(\text { ECEARTH })\end{array}$ & $\begin{array}{l}\text { historical } \\
\text { RCP8.5+ }\end{array}$ & 1,270 & $160 \times 320$ & $292 \times 362 \times 42$ & 508 & $\begin{array}{l}\text { Hazeleger et al. (20I2) } \\
\text { Svendsen et al. (20I5) }\end{array}$ \\
\hline $\begin{array}{l}\text { ECHAM5/MPIOM } \\
\text { (ECHAM5) }\end{array}$ & $\begin{array}{l}\text { abrupt } 4 x \\
\text { Ipct } 4 x\end{array}$ & $\begin{array}{l}1,000 \\
6,080\end{array}$ & $48 \times 96$ & $101 \times 120 \times 40$ & 100 & $\begin{array}{l}\text { Jungclaus et al. (2006) } \\
\text { Li et al. (2013) }\end{array}$ \\
\hline $\begin{array}{l}\text { FAMOUS } \\
\text { (FAMOUS) }\end{array}$ & $\begin{array}{l}\text { abrupt } 2 x \\
\text { abrupt } 4 x\end{array}$ & $\begin{array}{l}3,000 \\
3,000\end{array}$ & $37 \times 48$ & $73 \times 96 \times 20$ & 3,000 & Smith et al. (2008) \\
\hline $\begin{array}{l}\text { GFDL CM3 } \\
\text { (GFDLCM3) }\end{array}$ & Ipct $2 x$ & 5,000 & $90 \times 144$ & $200 \times 360 \times 50$ & 5,200 & $\begin{array}{l}\text { Donner et al. (20II) } \\
\text { Paynter et al. (2018) }\end{array}$ \\
\hline $\begin{array}{l}\text { GFDL-ESM2M } \\
\text { (GFDLESM2M) }\end{array}$ & Ipct2x & 4,500 & $90 \times 144$ & $200 \times 360 \times 50$ & 1,340 & $\begin{array}{l}\text { Dunne et al. (2012) } \\
\text { Paynter et al. (2018) }\end{array}$ \\
\hline $\begin{array}{l}\text { GISS-E2-R } \\
\text { (GISSE2R) }\end{array}$ & $\begin{array}{l}\text { abrupt } 4 x \\
\text { Ipct } 4 x\end{array}$ & 5,000 & $90 \times 144$ & $180 \times 288 \times 32$ & 5,225 & $\begin{array}{l}\text { Schmidt et al. (20l4), } \\
\text { Miller et al. (20|4), and } \\
\text { Nazarenko et al. (20l5) } \\
\text { Rind et al. (20|8) }\end{array}$ \\
\hline $\begin{array}{l}\text { HadCM3L } \\
(\operatorname{HadCM} 3 \mathrm{~L})\end{array}$ & $\begin{array}{l}\text { abrupt } 2 x \\
\text { abrupt } 4 x \\
\text { abrupt } 6 x \\
\text { abrupt8x }\end{array}$ & $\begin{array}{l}1,000 \\
1,000 \\
1,000 \\
1,000\end{array}$ & $73 \times 96$ & $73 \times 96 \times 20$ & 1,000 & $\begin{array}{l}\text { Cox et al. (2000) } \\
\text { Cao et al. (2016) }\end{array}$ \\
\hline $\begin{array}{l}\text { HadGEM2-ES } \\
\text { (HadGEM2) }\end{array}$ & abrupt $4 x$ & 1,328 & $145 \times 192$ & $216 \times 360 \times 40$ & 239 & $\begin{array}{l}\text { Collins et al. (20II) } \\
\text { Andrews et al. (20I5) }\end{array}$ \\
\hline $\begin{array}{l}\text { IPSL-CM5A-LR } \\
\text { (IPSLCM5ALR) }\end{array}$ & abrupt $4 x$ & 1,000 & $96 \times 96$ & $149 \times 182 \times 31$ & 1,000 & Dufresne et al. (20I3) \\
\hline $\begin{array}{l}\text { MIROC3.2 } \\
(\text { MIROC32) }\end{array}$ & $\begin{array}{l}\text { Ipct2x } \\
\text { Ipct } 4 x\end{array}$ & $\begin{array}{l}2,000 \\
2,000\end{array}$ & $64 \times 128$ & $192 \times 256 \times 44$ & 681 & $\begin{array}{l}\text { Hasumi and Emori (2004) } \\
\text { Yamamoto et al. (2015), } \\
\text { Yoshimori et al. (2016) }\end{array}$ \\
\hline $\begin{array}{l}\text { MPI-ESM-I.2 } \\
(\text { MPIESMI2) }\end{array}$ & $\begin{array}{l}\text { abrupt } 2 x \\
\text { abrupt } 4 x \\
\text { abrupt } 8 x \\
\text { abrupt16x }\end{array}$ & $\begin{array}{l}1,000 \\
1,000 \\
1,000 \\
1,000\end{array}$ & $96 \times 192$ & $220 \times 256 \times 40$ & 1,237 & $\begin{array}{l}\text { Mauritsen et al. (2018) } \\
\text { Rohrschneider et al. (2019) }\end{array}$ \\
\hline $\begin{array}{l}\text { MPI-ESM-I.I } \\
\text { (MPIESMII) }\end{array}$ & abrupt $4 x$ & 4,459 & $96 \times 192$ & $220 \times 256 \times 40$ & 2,000 & Mauritsen et al. (2018) \\
\hline
\end{tabular}



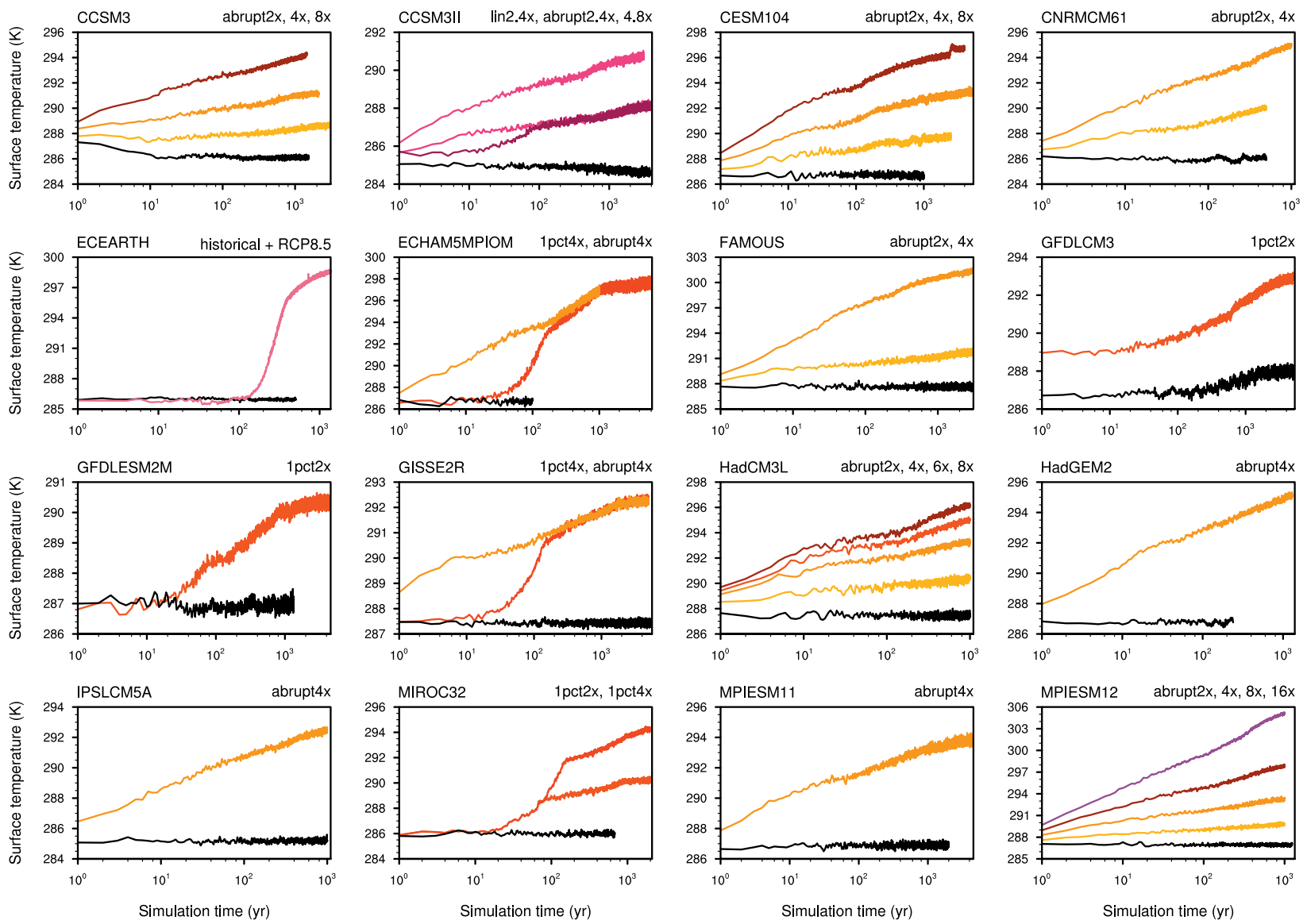

Fig. 2. Global- and annual-mean surface air temperature for control (black) and forced (colors; listed in the top right of each panel) simulations. Abrupt2x, abrupt4x, abrupt6x, and abrupt8x means that the $\mathrm{CO}_{2}$ concentration is doubled, quadrupled, sextupled, and octupled, respectively, as a step forcing branched off the control

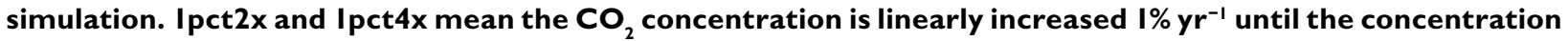
is doubled or quadrupled, respectively. The simulations of ECEARTH and CCSM3II are described in the "Minimal, optimal, and current contributions" section. Note the different axis ranges for each model. GFDLCM3 and CCSM3II are not branched off directly from the control simulation.

show no substantial drift, still have a constant energy leakage. For CMIP5 models, imbalances of the same order of magnitude (and larger) have been shown to be uncorrelated with the forced response (Hobbs et al. 2016). If computing atmospheric anomalies, we suggest users to take the difference of each time step to the time-averaged control simulation imbalance, except for CCSM3II and GFDLCM3 for which the difference to a polynomial fit to the control simulation time series seems appropriate (see Fig. 3).

The deep ocean (defined here as depth level around $2 \mathrm{~km}$ ) has an astonishingly small drift in the global average in most models (Fig. 4c). While the surface ocean time scales closely follow the global-mean surface air temperature anomaly, the deep ocean takes centuries to equilibrate. Figures $4 \mathrm{a}$ and $4 \mathrm{~b}$ display the surface and deep ocean temperature anomalies, computed as the difference of the forced and control simulations, while Fig. $4 \mathrm{c}$ shows the absolute temperatures of the deep ocean in the control simulations to indicate the model spread in the base state. Previous work on long-term trends in deep ocean temperature and salinity shows that these trends may reflect ongoing changes in stratification and the strength and depth of the Atlantic meridional overturning circulation (AMOC; e.g., Stouffer and Manabe 2003; Rugenstein et al. 2016a; Marzocchi and Jansen 2017; Jansen et al. 2018). Even if the energy flux imbalance at the TOA or the ocean surface are close to a new steady state this does not necessarily indicate that the deep ocean is equilibrated as well (Zhang et al. 2013; Hobbs et al. 2016; Marzocchi and Jansen 2017). Reaching deep ocean equilibration may not be necessary for studies concerned with surface properties only. However, for interpretation of paleo proxies and comparison with model simulations, distinguishing between the transient and equilibrium response in the intermediate or deep ocean is 

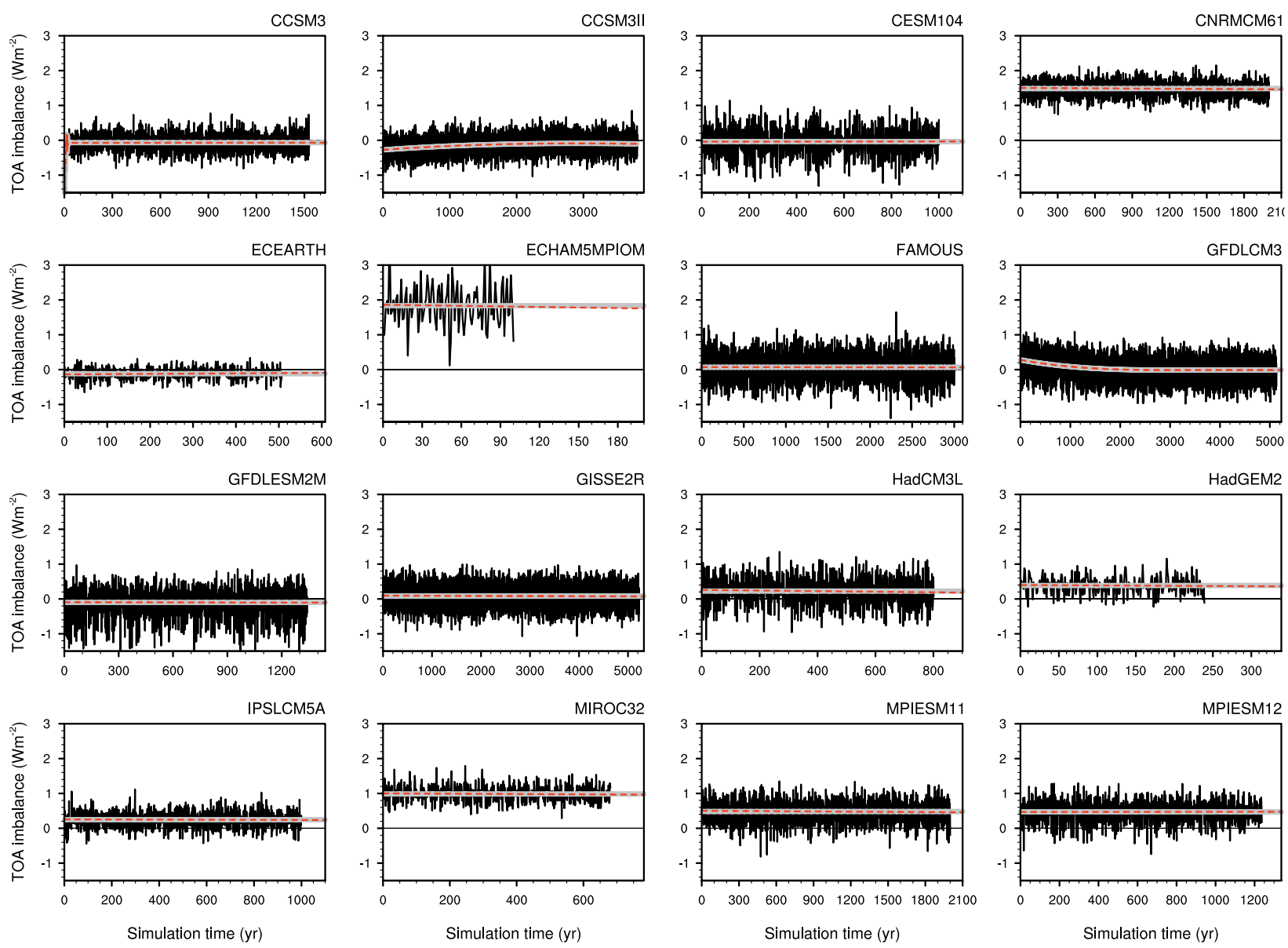

FIG. 3. TOA global- and annual-mean radiative imbalance of all control simulations. Note the different lengths of the horizontal axes. The gray line indicates the average and the red line the linear trend, except for CCSM3II and GFDLCM3, for which both colors depict a fourth-order polynomial fit.

necessary (Zhang et al. 2013; Marzocchi and Jansen 2017; Rind et al. 2018; Jansen et al. 2018).

Evolution of surface temperature and cloud radiative effect. The evolution of large-scale surface air temperature patterns on decadal to millennial time scales (Fig. 5) is robust among models and different forcing levels. The simulations show a strong land-sea warming contrast on short time scales and little warming over the Southern Ocean on decadal to centennial time scales (e.g., Manabe et al. 1991; Gregory 2000; Joshi and Gregory 2008; Geoffroy and Saint-Martin 2014; Armour et al. 2016). A warming pattern reminiscent of the positive phase of ENSO and the interdecadal Pacific oscillation occurs throughout the Pacific basin (Fig. 5b; Held et al. 2010; Song and Zhang 2014; Andrews et al. 2015; Luo et al. 2017) but decays on centennial to millennial time scales (Figs. 5c,d), with a large model spread in time scales (not shown). As it approaches equilibrium, the temperature pattern becomes more homogeneous, the land-sea warming contrast decreases (e.g., Held et al. 2010; Geoffroy and Saint-Martin 2014), and the Southern Hemisphere high latitudes keep warming beyond year 1000. As in previous studies, the AMOC first declines (Gregory et al. 2005; Zhu et al. 2015; Kostov et al. 2014; Trossman et al. 2016) and then recovers (Stouffer and Manabe 2003; Li et al. 2013; Zickfeld et al. 2013; Rugenstein et al. 2016a; Rind et al. 2018), resulting in a delayed warming in the North Atlantic. Figures 5a, 5b, and 5e correspond to the blue shading in Fig. 1, and are known from CMIP5 simulations (e.g., Andrews et al. 2015), while Figs. 5c, $5 \mathrm{~d}, 5 \mathrm{f}$, and $5 \mathrm{~g}$ highlight that the simulations still warm substantially on centennial to millennial time scales, mainly in areas with more sensitive (i.e., positive or small negative) feedbacks (Rugenstein et al. 2019).

Normalizing the zonal-mean temperature anomaly by the global-mean warming reveals the relative zonal-mean warming (Fig. 6). Arctic amplification begins very early in the simulations and warming throughout the Southern Hemisphere is lower than 

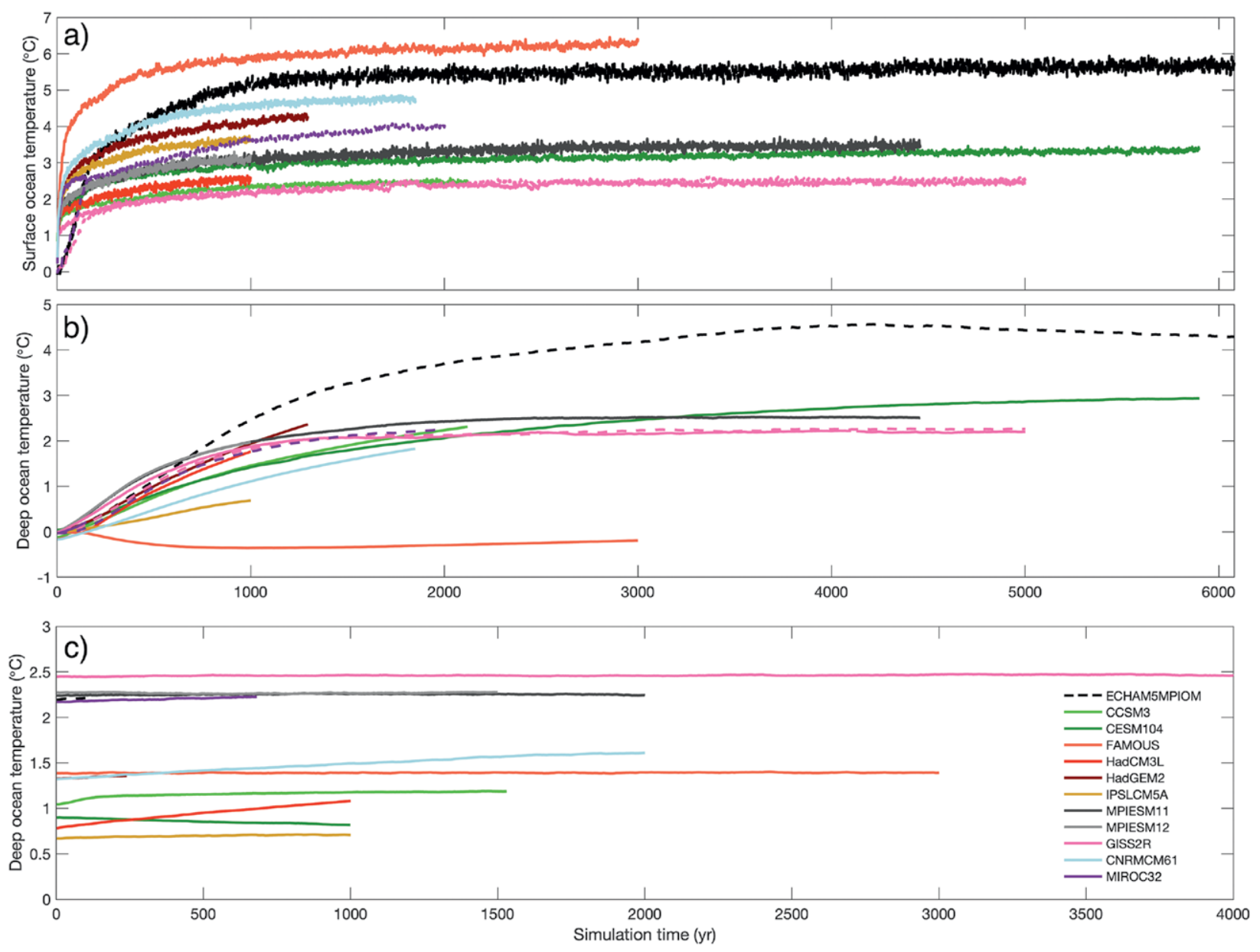

Fıg. 4. Global- and annual-mean temperature anomalies (experiment minus average of the control simulation) of the (a) surface ocean (first layer) and (b) deep ocean, as well as (c) absolute values of deep ocean temperature in the control simulations, for abrup4x (solid) and Ipct4x (dashed) simulations. "Deep ocean" means around $2-\mathrm{km}$ depth (closest level). Note that the time scale in (c) is shorter than in (a) and (b).

the global average in almost all models for the first centuries. Between year 100 and 1000 the Southern Hemisphere warms more than the Northern Hemisphere in all latitudes poleward from $30^{\circ}$, in some regions by more than $4 \mathrm{~K}$ (Fig. 5f). Antarctic warming slowly increases, but is still substantially less than Arctic amplification (e.g., Salzmann 2017). In a couple of models, the amplitude of Antarctic and Arctic amplification is the same after 4,000 years of model integration time (GISSE2R and ECHAM5; Li et al. 2013), while in other models the Antarctic amplification stays substantially smaller, though still increasing after a couple of thousand years. LongRunMIP shows that there is no reduction in model spread in the polar regions through time and that although all models follow a similar large-scale pattern evolution (Fig. 5), the local response time scales, for example, in the North Atlantic, Southern Ocean, or equatorial Pacific differ by hundreds to thousands years.
While the large-scale temperature response is rather robust between models and simulations, the cloud radiative effect (CRE) differs strongly in magnitude and time evolution, both between models and between forcing levels for the same model (Fig. 7). We show the shortwave CRE-computed as the difference between "all sky" and "clear sky" shortwave radiative fluxes (e.g., Ramanathan et al. 1989; Ceppi et al. 2017) — as a function of surface air temperature anomaly. The models disagree in the overall sign, as expected from CMIP5 models on shorter time scales (e.g., Vial et al. 2013; Caldwell et al. 2016), but can even change sign within a single simulation (e.g., ECEARTH or CESM abrupt8x). The strength of variation in time within one simulation can depend strongly on the forcing level (e.g., MIROC32 1pct2x vs 1pct4x) and the time scales of change differ between the models (e.g., IPSLCM5R vs MPIESM12 abrupt4x). For some simulations, the cloud response barely changes with temperature, 
contributing negligibly to the overall feedback (e.g., MPIESM12 abrupt16x, CESM104 abrupt4x, and MIROC32 1pct2x).

DISCUSSION AND OUTLOOK. Published millennial-length simulations. Models of intermediate complexity are the most common tools used to study century to millennium time scales in the climate system (e.g., Zickfeld et al. 2013; Eby et al. 2013;

\section{a) Temperature anomaly year $15-25$}

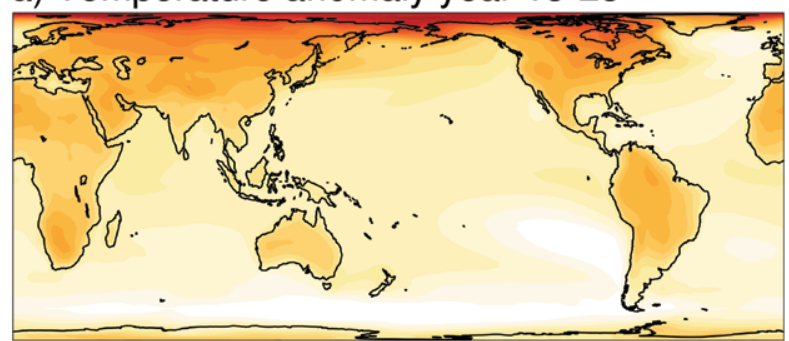

b) Temperature anomaly year $80-120$

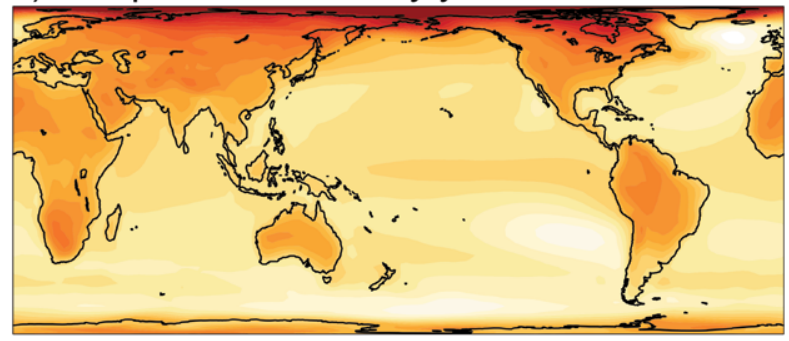

c) Temperature anomaly year $900-1000$

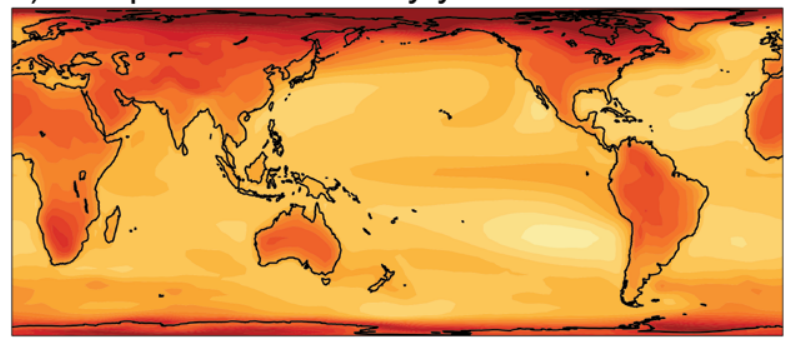

d) Temperature anomaly year $4000-4200$

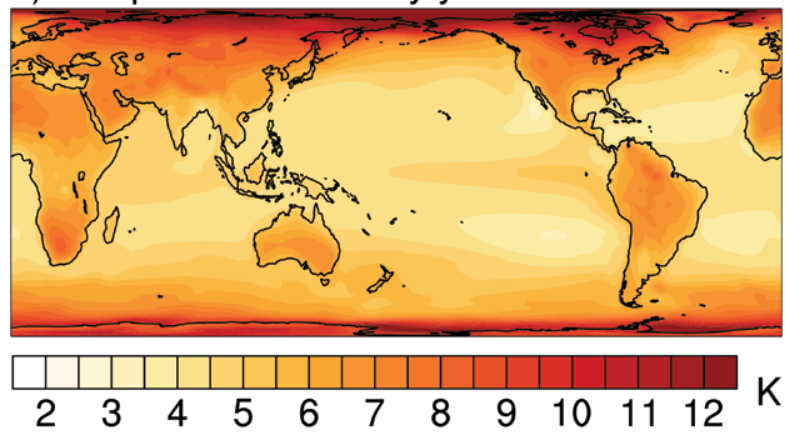

Levermann et al. 2013; Rugenstein et al. 2016c; Jansen et al. 2018). However, they usually have a poorly resolved atmosphere and little or no representation of cloud processes. In contrast, the publications in Table 3 feature millennium-length AOGCM simulations. These papers provide a solid body of work on millennial-length climate simulations, but rarely use the same forcing levels and simulation length and focus on different aspects of the climate system. Three papers compare model formulation and processes of two AOGCMs each (Frölicher et al. 2014; Paynter et al. 2018; Krasting et al. 2018), but otherwise models have not been systematically compared against each other. Figures 4 and 7 show that AOGCMs can strongly differ in their behavior. Spatial patterns of, for example, precipitation and surface heat fluxes also vary strongly between models and between different forcing scenarios for the same model (not
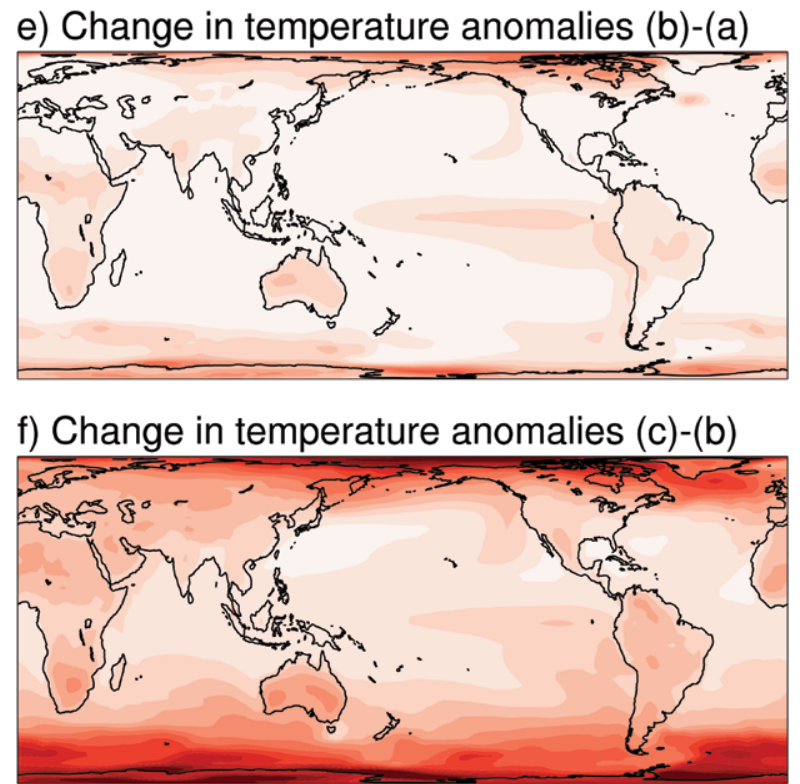

\section{g) Change in temperature anomalies (d)-(c)}

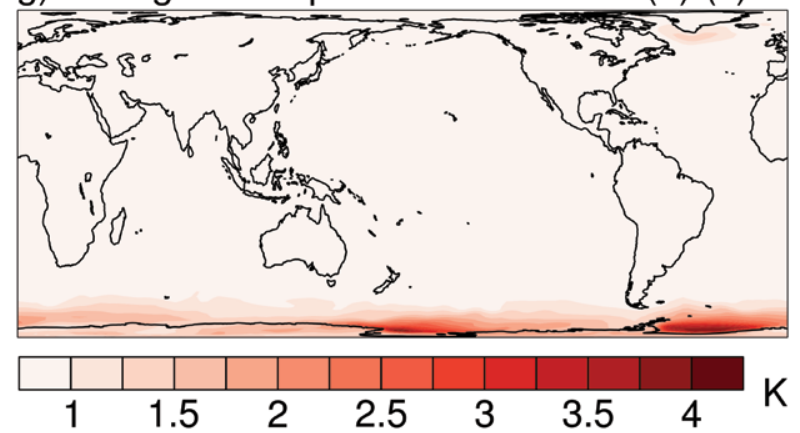

FIG. 5. Time evolution of the surface air temperature anomaly in the abrupt4x simulations. Models means include (a)-(c),(e),(f) CCSM3, CESMI04, CNRMCM6I, ECHAM5, GISSE2R, HadCM3L, HadGEM2, IPSLCM5A, MPIESMII, and MPIESMI 2 and (d),(g) only CESMI04, GISSE2R, and MPIESMII because of the length of these contributions. See Table 2 for details of the length of each simulation. 
shown), suggesting that some mechanisms and processes discussed in the published literature are not generalizable across models. For example, there is disagreement about which regions are thought to

a) Warming pattern year $15-25$

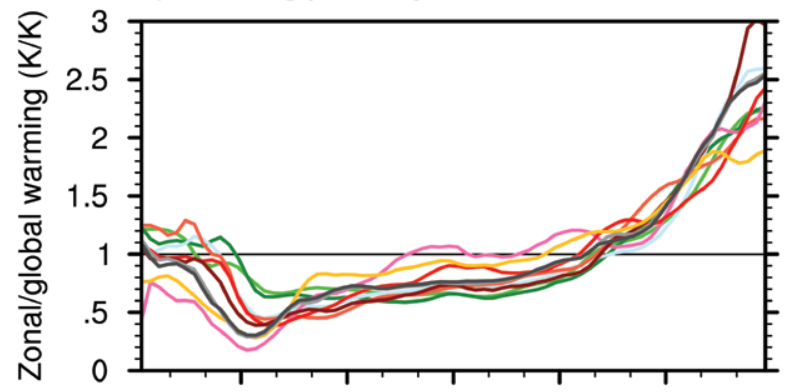

b) Warming pattern year $80-120$

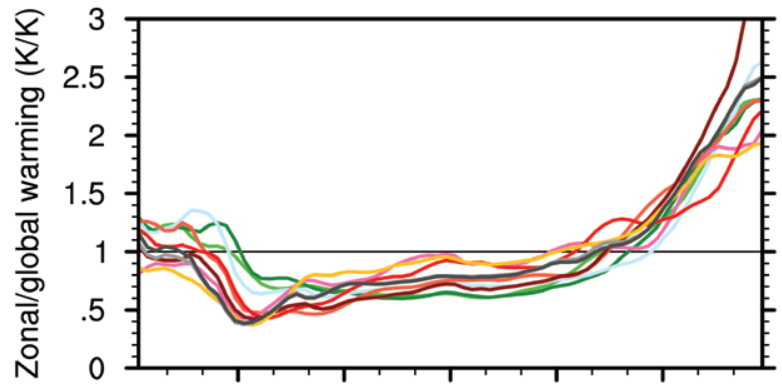

c) Warming pattern year $900-1000$

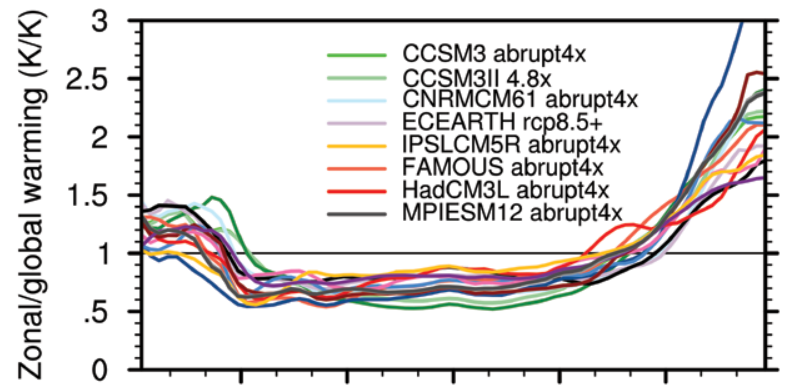

d) Warming pattern year $4000-4200$

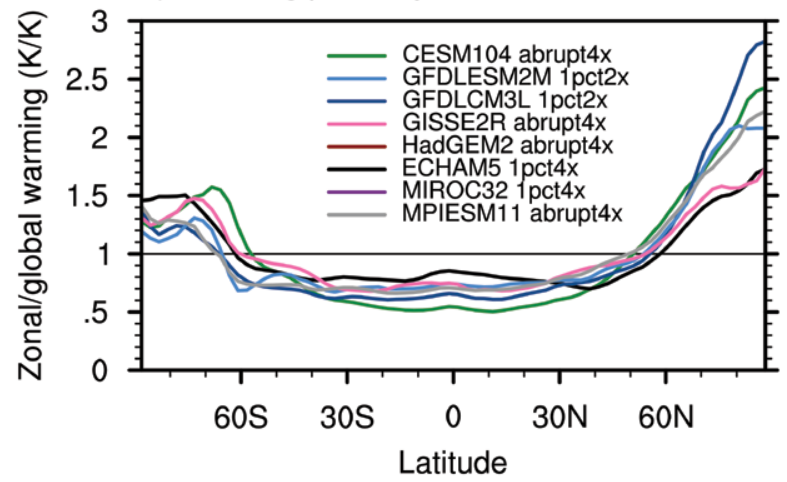

dominate the changing feedback parameter (Senior and Mitchell 2000; Andrews et al. 2015; Meraner et al. 2013; Caballero and Huber 2013) or whether or not, and on which time scales, the AMOC recovers from its initial reduction (Voss and Mikolajewicz 2001; Stouffer and Manabe 2003; Li et al. 2013; Rind et al. 2018; Thomas and Fedorov 2019). Paleoclimate simulations are often several thousand years long; however, they usually include boundary conditions such as ice sheets or changing continental configurations, which differ from the ones used here. However, paleoclimate studies often discuss equilibration time scales and deep ocean temperature trends relevant to the types of models included in LongRunMIP (e.g.,
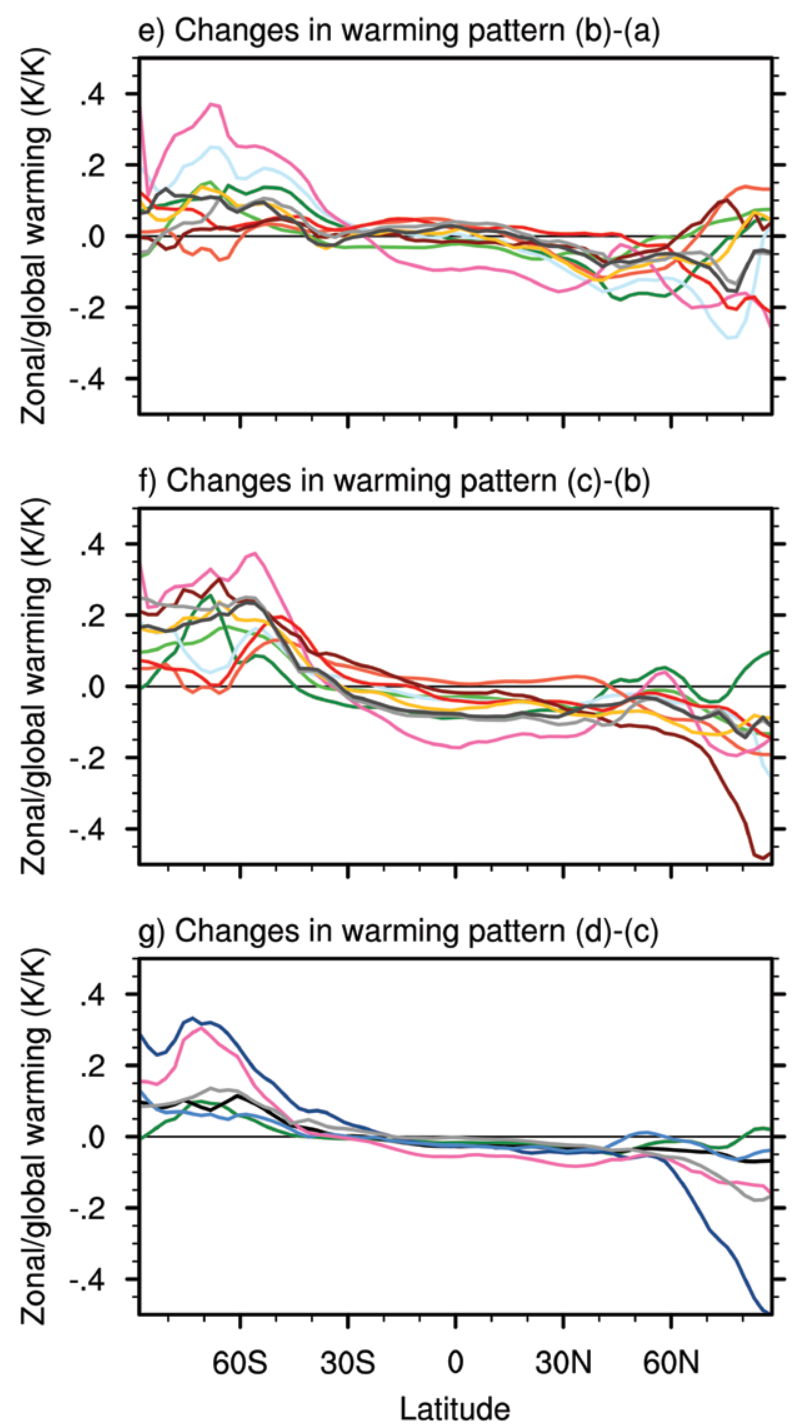

FIG. 6. Time evolution of the zonal-mean surface air temperature response normalized by the global-mean temperature anomaly. (a)-(d) Values above (below) I mean that warming is amplified (reduced) relative to the global-mean warming. (e)-(g) The differences (note the different scale). The plots in (a), (b), (e), and (f) contain only abrupt $4 x$ simulations, while the plots in (c), (d), and (g) also contain the Ipct $2 x$ and RCP8.5+ simulations with integration lengths longer than 4,000 years. Table 2 lists all simulations and model long names. 

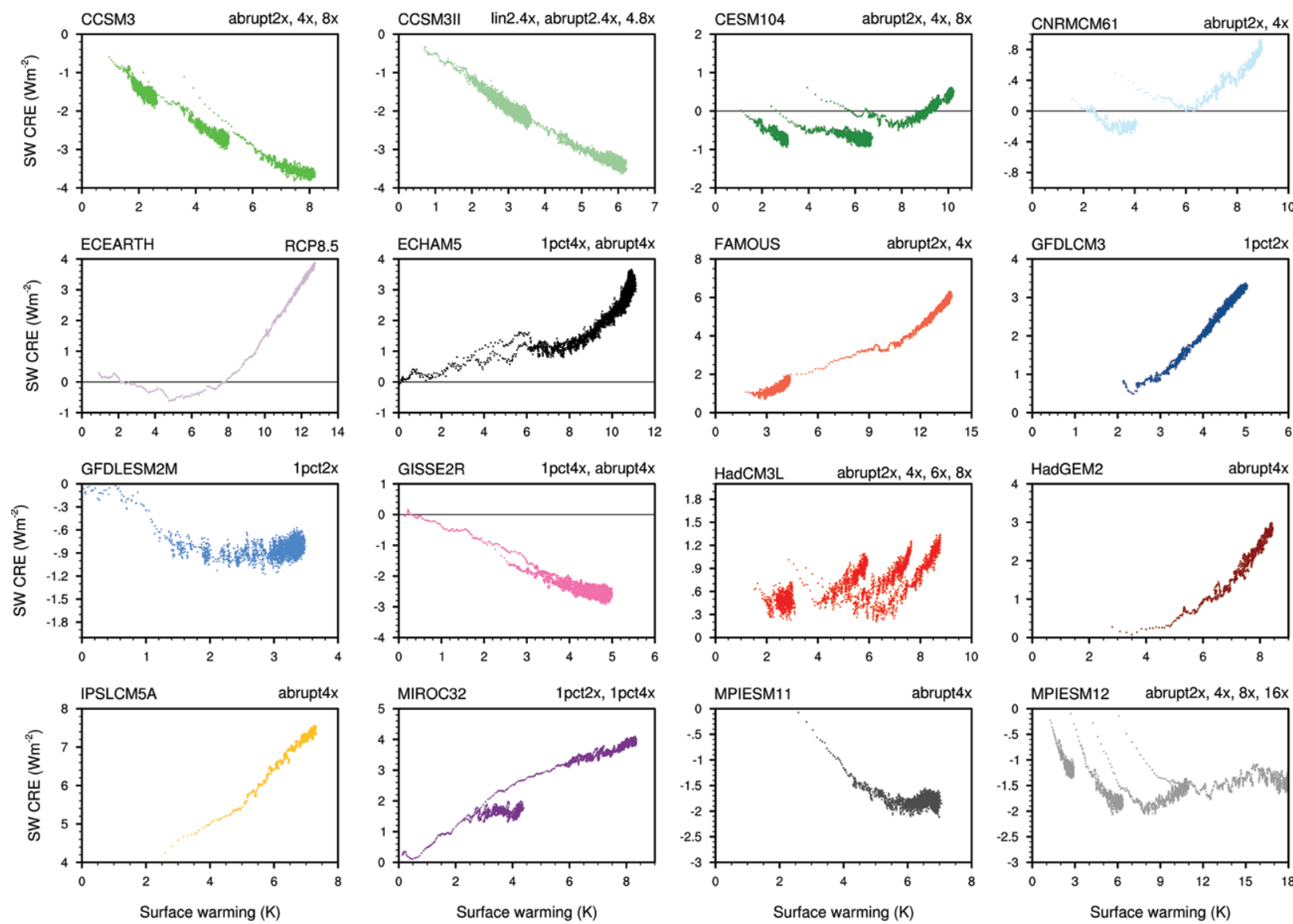

FIG. 7. Simulated shortwave cloud radiative effects (SW CRE) for different levels of global surface air temperature changes. Each point is a $\mathbf{1 0}$-yr running average. Note the different axes values, which cover a large range in TOA imbalance and surface temperature. Table 2 lists all simulations and model long names.

Brandefelt and Otto-Bliesner 2009; Zhang et al. 2013; Klockmann et al. 2016; Marzocchi and Jansen 2017; Gottschalk et al. 2019).

Limitations. LongRunMIP analyses are currently limited mainly by the collected variables (Table 1). Including cloud fields and 3D atmospheric temperature and humidity fields, for example, would allow users to study atmospheric dynamics and radiative feedbacks in more detail. The different forcing scenarios of model contributions to LongRunMIP are both a strength and weakness. Minimal requirements have encouraged a large number of contributions so far. However, studying a single forcing scenario requires model selection or scaling between different forcing levels. Slab-ocean simulations, which replace a model's dynamical ocean with a much shallower nondynamical mixed layer, are a computationally cheap tool to compare fast and slow time scales and the relevance of surface warming patterns (Boer and Yu 2003c; Danabasoglu and Gent 2009; Li et al. 2013). We hope to receive submissions of these simulations in the future, to allow analysis of their utility. Century to millennial time scales in the real world include more processes and Earth system feedbacks than are included in LongRunMIP simulations, such as the carbon cycle, vegetation feedbacks, forcing agents other than $\mathrm{CO}_{2}$ (such as other greenhouse gases or aerosols), ice sheets, glacial rebound effects, changes to continental configuration, and orbital variation. Further, the real climate system is never in equilibrium or steady state, because the forcing continuously changes (e.g., Köhler et al. 2017). These Earth system feedbacks and additional forcings must be taken into account when comparing the LongRunMIP models with paleo proxies or when projecting or predicting changes in future centuries or millennia.

Summary and expected impact. LongRunMIP is the first archive of millennial-length simulations of complex climate models, featuring 50 simulations of 15 models by 10 modeling centers under various forcing scenarios (Table 2). The archive provides an unprecedented opportunity to study the equilibrium 


\begin{tabular}{|c|c|c|c|c|}
\hline Paper & Model & $\begin{array}{l}\text { Forcing } \\
\text { level }\end{array}$ & $\begin{array}{l}\text { Length } \\
\text { (yr) }\end{array}$ & Content/scientific comment \\
\hline Senior and Mitchell (2000) & HadCM2 & $2 \times \mathrm{CO}_{2}$ & $\approx 800$ & $\begin{array}{l}\text { Included flux adjustments; effective climate } \\
\text { sensitivity increases due to SW CRE due to } \\
\text { changes in the interhemispheric tempera- } \\
\text { ture gradient }\end{array}$ \\
\hline Bi et al. (200I) & CSIRO & $3 \times \mathrm{CO}_{2}$ & $\approx 1,000$ & $\begin{array}{l}\text { Cessation and recovery of Antarctic Bottom } \\
\text { Water and North Atlantic Deep Water } \\
\text { formation }\end{array}$ \\
\hline Voss and Mikolajewicz (200I) & ECHAM3 & $2 \times, 4 \times \mathrm{CO}_{2}$ & 850 & $\begin{array}{l}\text { Adjustment time scales, committed warming, } \\
\text { ocean thermohaline circulation }\end{array}$ \\
\hline Stouffer and Manabe $(1999,2003)$ & GFDL & $\begin{array}{l}0.5 \times, 2 \times \\
4 \times \mathrm{CO}_{2}\end{array}$ & 4,000 & $\begin{array}{l}\text { Thermohaline circulation and paleo-oceano- } \\
\text { graphic implications }\end{array}$ \\
\hline Boer and Yu $(2003 a, b, c)$ & CCCma & $\begin{array}{l}\text { Twenty-first } \\
\text { century }\end{array}$ & 1,000 & $\begin{array}{l}\text { Radiative feedbacks and surface warming; } \\
\text { effective climate sensitivity decreases with } \\
\text { time; slab vs fully coupled models }\end{array}$ \\
\hline Gregory et al. (2004) & HadCM3 & $2 \times \mathrm{CO}_{2}$ & $\approx 1,000$ & $\begin{array}{l}\text { TOA radiative imbalance and surface tem- } \\
\text { perature are not linearly related; after } 1,000 \\
\text { years the model is still } 0.7 \mathrm{~W} \mathrm{~m}^{-2} \text { away from } \\
\text { equilibrium }\end{array}$ \\
\hline Danabasoglu and Gent (2009)* & CCSM3 & $\begin{array}{l}2 \times 4 \times \\
8 \times \mathrm{CO}_{2}\end{array}$ & 3,000 & $\begin{array}{l}\text { Comparing slab and fully coupled models; } \\
\text { determining ECS; Jonko et al. (2013) analyzed } \\
\text { the contributions of different feedbacks to } \\
\text { doublings of } \mathrm{CO}_{2}\end{array}$ \\
\hline Gillett et al. (20II) & CanESMI & $\begin{array}{l}\text { Twenty-first } \\
\text { century }\end{array}$ & $\approx 1,000$ & Impact of reduced emissions \\
\hline Li et al. $(2013)^{*}$ & $\begin{array}{l}\text { ECHAM5/ } \\
\text { MPI-OM }\end{array}$ & $2 \times \mathrm{CO}_{2}$ & $\approx 6,000$ & $\begin{array}{l}\text { Comparing slab and fully coupled models; } \\
\text { determining ECS; adjustment time scales of } \\
\text { surface warming patterns, ocean heat uptake, } \\
\text { and sea level rise }\end{array}$ \\
\hline $\begin{array}{l}\text { Frölicher et al. (2014) and } \\
\text { Frölicher and Paynter (2015) }\end{array}$ & $\begin{array}{l}\text { GFDL-ESM2M, } \\
\text { CSMI }\end{array}$ & $\begin{array}{l}4 \times \mathrm{CO}_{2} \\
\text { pulse }\end{array}$ & 1,000 & $\begin{array}{l}\text { Climate impact of } \mathrm{CO}_{2} \text { emission stoppage; } \\
\text { evolving feedbacks; } \mathrm{ECS} \text {; transient climate } \\
\text { response to cumulative carbon emissions }\end{array}$ \\
\hline Andrews et al. (2015)* & HadGEM2-ES & $4 \times \mathrm{CO}_{2}$ & $\approx 1,300$ & $\begin{array}{l}\text { Nonconstancy of feedbacks; variations of } \\
\text { TOA components cancel each other on the } \\
\text { century to millennial time scale }\end{array}$ \\
\hline $\begin{array}{l}\text { Yamamoto et al. (2015)* and } \\
\text { Yoshimori et al. (2016) }\end{array}$ & MIROC3.2 & $2 \times, 4 \times \mathrm{CO}_{2}$ & 2,000 & $\begin{array}{l}\text { Deep ocean ventilation overall increases } \\
\text { oxygenation after a transient decrease; re- } \\
\text { view article on ocean heat uptake in coupled } \\
\text { models and energy balance models }\end{array}$ \\
\hline Cao et al. $(2016) *$ & HadCM3L & $\begin{array}{l}2 \times, 4 \times, 6 \times \\
8 \times \mathrm{CO}_{2}\end{array}$ & 1,000 & $\begin{array}{l}\text { Comparing } \mathrm{CO}_{2} \text { to other forcing agents and } \\
\text { geoengineering scenarios }\end{array}$ \\
\hline Rugenstein et al. $(2016 a, b)^{*}$ & CESMI04 & $\begin{array}{l}2 \times 4 \times \\
8 \times \mathrm{CO}_{2}\end{array}$ & $\approx 1,300$ & $\begin{array}{l}\text { Dependence of global and regional radiative } \\
\text { feedback evolution on surface heat flux pat- } \\
\text { terns; forcing adjustment }\end{array}$ \\
\hline Paynter et al. $(2018)^{*}$ & $\begin{array}{l}\text { GFDL-ESM2M, } \\
\text { GFDL CM3 }\end{array}$ & $2 \times \mathrm{CO}_{2}$ & $\approx 5,000$ & $\begin{array}{l}\text { Evolution of global and regional radiative } \\
\text { feedbacks and the role of atmospheric verti- } \\
\text { cal velocity fields and inversion strengths }\end{array}$ \\
\hline Rind et al. (2018)* & GISS-E2-R & $4 \times \mathrm{CO}_{2}$ & $\approx 2,000$ & $\begin{array}{l}\text { AMOC reduction and recovery on North } \\
\text { Atlantic surface flux conditions }\end{array}$ \\
\hline Krasting et al. (2018) & $\begin{array}{l}\text { GFDL-ESM2Mb, } \\
\text { GFDL-ESM2G }\end{array}$ & $4 \times \mathrm{CO}_{2}$ & 5,000 & $\begin{array}{l}\text { Ocean heat uptake, model formulation of dia- } \\
\text { pycnal diffusivity and ocean vertical coordinates }\end{array}$ \\
\hline
\end{tabular}

*Contribution to LongRunMIP. 
response of a large number of models to forcing. The variables included allow study of a range of phenomena associated with the atmosphere, ocean, land, and sea ice (Table 1), and we expect LongRunMIP to contribute to current discussions laid out in the first section. This includes ocean heat uptake, sea level rise, ocean circulation response to warming, largescale modes of variability, sea ice reduction, polar amplification, precipitation variability, atmospheric dynamics, long-term memory in time series, spatial warming patterns, ocean-atmosphere interactions, model spinup techniques, the relation of internal variability and forced response under different forcing levels, committed climate response, and the relation of time and state dependence of fast feedbacks and Earth system feedbacks and processes.

LongRunMIP is a MIP of opportunity, without an agreed-upon protocol, and is a result of the willingness of individual research groups to provide model output from simulations often conducted over years of real-world time. As a result, the experiments are not standardized, but most models provided a millennial-length simulation that begins with an abrupt quadrupling of $\mathrm{CO}_{2}$ concentration. In addition to collecting simulations, we provide output with standardized formats and variable names, and include versions regridded to a common grid, as well as global averages.

LongRunMIP builds upon a body of pioneering studies that looked at the behavior of models beyond the centennial scale (Table 3), LongRunMIP allows this sort of analysis to be applied across a diverse group of models that exhibit strikingly different behavior (Fig. 7), and hopefully encourages others to look beyond the limitations and assumptions normally imposed by computational constraints, to directly study the equilibration of the fully coupled atmosphere-ocean system.

Data access and sharing. LongRunMIP currently consists of $15 \mathrm{~TB}$ of data and are available for download (https://data.iac.ethz.ch/longrunmip/). Fields shown in this paper can be accessed online (https://data.iac .ethz.ch/longrunmip/BAMS/). See www.longrunmip .org for more details on available variables, contact information, sample figures and videos (see supplemental material), and links to join a discussion community. We will be collecting more simulations over the next couple of years.

ACKNOWLEDGMENTS. MR acknowledges support from the Swiss National Science Foundation under Grant P2EZP2_175097 and is funded by the Alexander von
Humboldt Foundation. TA was supported by the Joint U.K. BEIS/Defra Met Office Hadley Centre Climate Programme (GA01101). NCAR is a major facility sponsored by the U.S. National Science Foundation under Cooperative Agreement 1852977. TLF acknowledges support from the Swiss National Science Foundation under Grant PP00P2_170687, from the European Union's Horizon 2020 research and innovation program under Grant Agreement 821003 (CCiCC), and from the Swiss National Supercomputing Centre (CSCS). CL was supported through the Clusters of Excellence CliSAP (EXC177) and CLICCS (EXC2037), University Hamburg, funded through the German Research Foundation (DFG). SY was partly supported by European Research Council under the European Community's Seventh Framework Programme (FP7/20072013)/ERC Grant Agreement 610055 as part of the ice2ice project. This work was made possible for IPSL thanks to the HPC resources of TGCC and IDRIS made available by GENCI (Grand Equipement National de Calcul Intensif), CEA (Commissariat à l'Energie Atomique et aux Energies Alternatives), and CNRS (Centre National de la Recherche Scientifique) (Project 016178).

\section{REFERENCES}

Andrews, T., and M. J. Webb, 2018: The dependence of global cloud and lapse rate feedbacks on the spatial structure of tropical Pacific warming. J. Climate, 31, 641-654, https://doi.org/10.1175/JCLI-D-17-0087.1.

— J. M. Gregory, and M. J. Webb, 2015: The dependence of radiative forcing and feedback on evolving patterns of surface temperature change in climate models. J. Climate, 28, 1630-1648, https://doi.org /10.1175/JCLI-D-14-00545.1.

—-, and Coauthors, 2018: Accounting for changing temperature patterns increases historical estimates of climate sensitivity. Geophys. Res. Lett., 45, 84908499, https://doi.org/10.1029/2018GL078887.

Armour, K. C., 2017: Energy budget constraints on climate sensitivity in light of inconstant climate feedbacks. Nat. Climate Change, 7, 331-335, https:// doi.org/10.1038/nclimate3278.

—, C. M. Bitz, and G. H. Roe, 2013: Time-varying climate sensitivity from regional feedbacks. J. Climate, 26, 4518-4534, https://doi.org/10.1175/JCLI-D $-12-00544.1$.

- J. Marshall, J. R. Scott, A. Donohoe, and E. R. Newsom, 2016: Southern ocean warming delayed by circumpolar upwelling and equatorward transport. Nat. Geosci., 9, 549-554, https://doi.org/10.1038 /ngeo2731.

Bi, D., W. F. Budd, A. C. Hirst, and X. Wu, 2001: Collapse and reorganisation of the Southern Ocean 
overturning under global warming in a coupled model. Geophys. Res. Lett., 28, 3927-3930, https:// doi.org/10.1029/2001GL013705.

Bilbao, R. A., J. M. Gregory, and N. Bouttes, 2015: Analysis of the regional pattern of sea level change due to ocean dynamics and density change for 1993-2099 in observations and CMIP5 AOGCMs. Climate Dyn., 45, 2647-2666, https://doi.org/10.1007 /s00382-015-2499-z.

Bloch-Johnson, J., R. T. Pierrehumbert, and D. S. Abbot, 2015: Feedback temperature dependence determines the risk of high warming. Geophys. Res. Lett., 42, 4973-4980, https://doi.org/10.1002/2015GL064240.

Block, K., and T. Mauritsen, 2013: Forcing and feedback in the MPI-ESM-LR coupled model under abruptly quadrupled $\mathrm{CO}_{2}$. J. Adv. Model. Earth Syst., 5, 676691, https://doi.org/10.1002/jame.20041.

Boer, G., and B. Yu, 2003a: Climate sensitivity and climate state. Climate Dyn., 21, 167-176, https://doi .org/10.1007/s00382-003-0323-7.

— and - 2003b: Climate sensitivity and response. Climate Dyn., 20, 415-429, https://doi.org/10.1007 /s00382-002-0283-3.

—, and —_, 2003c: Dynamical aspects of climate sensitivity. Geophys. Res. Lett., 30, 1135, https://doi .org/10.1029/2002GL016549.

Brandefelt, J., and B. L. Otto-Bliesner, 2009: Equilibration and variability in a Last Glacial Maximum climate simulation with CCSM3. Geophys. Res. Lett., 36, L19712, https://doi.org/10.1029/2009GL040364.

Brown, P. T., Y. Ming, W. Li, and S. A. Hill, 2017: Change in the magnitude and mechanisms of global temperature variability with warming. Nat. Climate Change, 7, 743-748, https://doi.org/10.1038/nclimate3381.

Burls, N. J., and A. V. Fedorov, 2017: Wetter subtropics in a warmer world: Contrasting past and future hydrological cycles. Proc. Natl. Acad. Sci. USA, 114, 12 888-12 893, https://doi.org/10.1073/pnas .1703421114 .

Caballero, R., and M. Huber, 2013: State-dependent climate sensitivity in past warm climates and its implications for future climate projections. Proc. Natl. Acad. Sci. USA, 110, 14 162-14 167, https://doi .org/10.1073/pnas.1303365110.

Caldwell, P. M., M. D. Zelinka, K. E. Taylor, and K. Marvel, 2016: Quantifying the sources of intermodel spread in equilibrium climate sensitivity. $J$. Climate, 29, 513-524, https://doi.org/10.1175/JCLI -D-15-0352.1.

Cao, L., L. Duan, G. Bala, and K. Caldeira, 2016: Simulated long-term climate response to idealized solar geoengineering. Geophys. Res. Lett., 43, 2209-2217, https://doi.org/10.1002/2016GL068079.
Castruccio, S., D. J. McInerney, M. L. Stein, F. Liu Crouch, R. L. Jacob, and E. J. Moyer, 2014: Statistical emulation of climate model projections based on precomputed GCM runs. J. Climate, 27, 1829-1844, https://doi.org/10.1175/JCLI-D-13-00099.1.

Ceppi, P., and J. M. Gregory, 2017: Relationship of tropospheric stability to climate sensitivity and Earth's observed radiation budget. Proc. Natl. Acad. Sci. USA, 114, 13 126-13 131, https://doi.org/10.1073 /pnas.1714308114.

—, F. Brient, M. D. Zelinka, and D. L. Hartmann, 2017: Cloud feedback mechanisms and their representation in global climate models. Wiley Interdiscip. Rev.: Climate Change, 8, e465, https://doi.org/10.1002 /wcc.465.

Charney, J., and Coauthors, 1979: Carbon dioxide and climate: A scientific assessment. Climate Research Board Tech. Rep., 22 pp.

Clark, P. U., and Coauthors, 2016: Consequences of twenty-first-century policy for multi-millennial climate and sea-level change. Nat. Climate Change, 6, 360-369, https://doi.org/10.1038/nclimate2923.

Collins, W. J., and Coauthors, 2011: Development and evaluation of an Earth-system model-HadGEM2. Geosci. Model Dev., 4, 1051-1075, https://doi.org /10.5194/gmd-4-1051-2011.

Colman, R., and B. McAvaney, 2009: Climate feedbacks under a very broad range of forcing. Geophys. Res. Lett., 36, L01702, https://doi.org/10.1029/2008GL036268.

_ , and L. Hanson, 2016: On the relative strength of radiative feedbacks under climate variability and change. Climate Dyn., 49, 2115-2129, https://doi .org/10.1007/s00382-016-3441-8.

Cox, P. M., R. A. Betts, C. D. Jones, S. A. Spall, and I. J. Totterdell, 2000: Acceleration of global warming due to carbon-cycle feedbacks in a coupled climate model. Nature, 408, 184-187, https://doi .org/10.1038/35041539.

Danabasoglu, G., and P. R. Gent, 2009: Equilibrium climate sensitivity: Is it accurate to use a slab ocean model? J. Climate, 22, 2494-2499, https://doi.org /10.1175/2008JCLI2596.1.

_ , S. G. Yeager, Y.-O. Kwon, J. J. Tribbia, A. S. Phillips, and J. W. Hurrell, 2012: Variability of the Atlantic meridional overturning circulation in CCSM4. J. Climate, 25, 5153-5172, https://doi.org/10.1175 /JCLI-D-11-00463.1.

Deser, C., A. Phillips, V. Bourdette, and H. Teng, 2012: Uncertainty in climate change projections: The role of internal variability. Climate Dyn., 38, 527-546, https://doi.org/10.1007/s00382-010-0977-x.

Donner, L. J., and Coauthors, 2011: The dynamical core, physical parameterizations, and basic simulation 
characteristics of the atmospheric component AM3 of the GFDL global coupled model CM3. J. Climate, 24, 3484-3519, https://doi.org/10.1175/2011JCLI 3955.1 .

Dufresne, J.-L., and Coauthors, 2013: Climate change projections using the IPSL-CM5 Earth system model: From CMIP3 to CMIP5. Climate Dyn., 40, 21232165, https://doi.org/10.1007/s00382-012-1636-1.

Dunne, J. P., and Coauthors, 2012: GFDL's ESM2 global coupled climate-carbon Earth system models. Part I: Physical formulation and baseline simulation characteristics. J. Climate, 25, 6646-6665, https:// doi.org/10.1175/JCLI-D-11-00560.1.

Eby, M., and Coauthors, 2013: Historical and idealized climate model experiments: An intercomparison of Earth system models of intermediate complexity. Climate Past, 9, 1111-1140, https://doi.org/10.5194 /cp-9-1111-2013.

Eyring, V., S. Bony, G. A. Meehl, C. A. Senior, B. Stevens, R. J. Stouffer, and K. E. Taylor, 2016: Overview of the Coupled Model Intercomparison Project phase 6 (CMIP6) experimental design and organization. Geosci. Model Dev., 9, 1937-1958, https://doi.org /10.5194/gmd-9-1937-2016.

Frölicher, T., and F. Joos, 2010: Reversible and irreversible impacts of greenhouse gas emissions in multi-century projections with the NCAR global coupled carbon cycle-climate model. Climate Dyn., 35, 1439-1459, https://doi.org/10.1007/s00382-009 $-0727-0$.

— - and D. J. Paynter, 2015: Extending the relationship between global warming and cumulative carbon emissions to multi-millennial timescales. Environ. Res. Lett., 10, 075002, https://doi.org/10.1088/1748 $-9326 / 10 / 7 / 075002$.

—, M. Winton, and J. L. Sarmiento, 2014: Continued global warming after $\mathrm{CO}_{2}$ emissions stoppage. Nat. Climate Change, 4, 40-44, https://doi.org/10.1038 /nclimate2060.

Gebbie, G., and P. Huybers, 2019: The Little Ice Age and 20th-century deep Pacific cooling. Science, 363, 70-74, https://doi.org/10.1126/science.aar8413.

Gent, P. R., and Coauthors, 2011: The Community Climate System Model version 4. J. Climate, 24, 4973-4991, https://doi.org/10.1175/2011JCLI4083.1.

Geoffroy, O., and D. Saint-Martin, 2014: Pattern decomposition of the transient climate response. Tellus, 66A, 232393, https://doi.org/10.3402/tellusa .v66.23393.

—, — D. J. L. Olivié, A. Voldoire, G. Bellon, and S. Tytéca, 2013a: Transient climate response in a two-layer energy-balance model. Part I: Analytical solution and parameter calibration using CMIP5
AOGCM experiments. J. Climate, 26, 1841-1857, https://doi.org/10.1175/JCLI-D-12-00195.1.

— — - G. Bellon, A. Voldoire, D. Olivié, and S. Tytéca, 2013b: Transient climate response in a two-layer energy-balance model. Part II: Representation of the efficacy of deep-ocean heat uptake and validation for CMIP5 AOGCMs. J. Climate, 26, 1859-1876, https:// doi.org/10.1175/JCLI-D-12-00196.1.

Gillett, N. P., V. K. Arora, K. Zickfeld, S. J. Marshall, and W. J. Merryfield, 2011: Ongoing climate change following a complete cessation of carbon dioxide emissions. Nat. Geosci., 4, 83-87, https://doi .org/10.1038/ngeo1047.

Good, P., J. Gregory, J. Lowe, and T. Andrews, 2013: Abrupt $\mathrm{CO}_{2}$ experiments as tools for predicting and understanding CMIP5 representative concentration pathway projections. Climate Dyn., 40, 1041-1053, https://doi.org/10.1007/s00382-012-1410-4.

— and Coauthors, 2015: Nonlinear regional warming with increasing $\mathrm{CO}_{2}$ concentrations. Nat. Climate Change, 5, 138-142, https://doi.org/10.1038/nclimate 2498.

—, T. Andrews, R. Chadwick, J.-L. Dufresne, J. M. Gregory, J. A. Lowe, N. Schaller, and H. Shiogama, 2016: nonlinMIP contribution to CMIP6: Model intercomparison project for non-linear mechanisms: Physical basis, experimental design and analysis principles (v1.0). Geosci. Model Dev., 9, 4019-4028, https://doi.org/10.5194/gmd-9-4019-2016.

Gottschalk, J., and Coauthors, 2019: Mechanisms of millennial-scale atmospheric $\mathrm{CO}_{2}$ change in numerical model simulations. Quat. Sci. Rev., 220, 30-74, https://doi.org/10.1016/j.quascirev.2019.05.013.

Gregory, J. M., 2000: Vertical heat transports in the ocean and their effect on time-dependent climate change. Climate Dyn., 16, 501-515, https://doi.org/10.1007 /s003820000059.

— - and Coauthors, 2004: A new method for diagnosing radiative forcing and climate sensitivity. Geophys. Res. Lett., 31, L03205, https://doi.org/10.1029 /2003GL018747.

_- and Coauthors, 2005: A model intercomparison of changes in the Atlantic thermohaline circulation in response to increasing atmospheric $\mathrm{CO}_{2}$ concentration. Geophys. Res. Lett., 32, L12703, https://doi .org/10.1029/2005GL023209.

—, T. Andrews, and P. Good, 2015: The inconstancy of the transient climate response parameter under increasing $\mathrm{CO}_{2}$. Philos. Trans. Roy. Soc. London, 373A, 20140417, https://doi.org/10.1098/rsta.2014 .0417 .

— — — - T. Mauritsen, and P. M. Forster, 2016: Small global-mean cooling due to volcanic radiative 
forcing. Climate Dyn., 47, 3979-3991, https://doi .org/10.1007/s00382-016-3055-1.

Hasumi, H., and S. Emori, 2004: K-1 coupled GCM (MIROC) description. K-1 Tech. Rep. 1, 39 pp.

Hazeleger, W., and Coauthors, 2012: EC-EARTH V2.2: Description and validation of a new seamless Earth system prediction model. Climate Dyn., 39, 26112629, https://doi.org/10.1007/s00382-011-1228-5.

Held, I., M. Winton, K. Takahashi, T. L. Delworth, F. Zeng, and G. Vallis, 2010: Probing the fast and slow components of global warming by returning abruptly to preindustrial forcing. J. Climate, 23, 2418-2427, https://doi.org/10.1175/2009JCLI3466.1.

Hobbs, W., M. D. Palmer, and D. Monselesan, 2016: An energy conservation analysis of ocean drift in the CMIP5 global coupled models. J. Climate, 29, 1639-1653, https://doi.org/10.1175/JCLI-D-15-0477.1.

Jansen, M. F., L.-P. Nadeau, and T. M. Merlis, 2018: Transient versus equilibrium response of the ocean's overturning circulation to warming. J. Climate, 31, 5147-5163, https://doi.org/10.1175/JCLI-D-17 $-0797.1$.

Jonko, A. K., K. M. Shell, B. M. Sanderson, and G. Danabasoglu, 2013: Climate feedbacks in CCSM3 under changing $\mathrm{CO}_{2}$ forcing. Part II: Variation of climate feedbacks and sensitivity with forcing. $J$. Climate, 26, 2784-2795, https://doi.org/10.1175/JCLI -D-12-00479.1.

Joshi, M., and J. Gregory, 2008: Dependence of the landsea contrast in surface climate response on the nature of the forcing. Geophys. Res. Lett., 35, L24802, https:// doi.org/10.1029/2008GL036234.

Jungclaus, J. H., and Coauthors, 2006: Ocean circulation and tropical variability in the coupled model ECHAM5/MPI-OM. J. Climate, 19, 3952-3972, https://doi.org/10.1175/JCLI3827.1.

Khon, V. C., B. Schneider, M. Latif, W. Park, and C. Wengel, 2018: Evolution of eastern equatorial Pacific seasonal and interannual variability in response to orbital forcing during the Holocene and Eemian from model simulations. Geophys. Res. Lett., 45, 9843-9851, https://doi.org/10.1029/2018GL079337.

Klockmann, M., U. Mikolajewicz, and J. Marotzke, 2016: The effect of greenhouse gas concentrations and ice sheets on the glacial AMOC in a coupled climate model. Climate Past, 12, 1829-1846, https:// doi.org/10.5194/cp-12-1829-2016.

Knutti, R., 2010: The end of model democracy? Climatic Change, 102, 395-404, https://doi.org/10.1007/s10584 -010-9800-2.

—, M. A. A. Rugenstein, and G. C. Hegerl, 2017: Beyond equilibrium climate sensitivity. Nat. Geosci., 10, 727-736, https://doi.org/10.1038/ngeo3017.
Köhler, P., C. Nehrbass-Ahles, J. Schmitt, T. F. Stocker, and H. Fischer, 2017: A 156 kyr smoothed history of the atmospheric greenhouse gases $\mathrm{CO}_{2}, \mathrm{CH}_{4}$, and $\mathrm{N}_{2} \mathrm{O}$ and their radiative forcing. Earth Syst. Sci. Data, 9, 363-387, https://doi.org/10.5194/essd-9-363-2017.

Kostov, Y., K. C. Armour, and J. Marshall, 2014: Impact of the Atlantic meridional overturning circulation on ocean heat storage and transient climate change. Geophys. Res. Lett., 41, 2108-2116, https://doi.org /10.1002/2013GL058998.

Krasting, J. P., R. J. Stouffer, S. M. Griffies, R. W. Hallberg, S. L. Malyshev, B. L. Samuels, and L. T. Sentman, 2018: Role of ocean model formulation in climate response uncertainty. J. Climate, 31, 9313-9333, https://doi.org/10.1175/JCLI-D $-18-0035.1$.

Levermann, A., P. U. Clark, B. Marzeion, G. A. Milne, D. Pollard, V. Radic, and A. Robinson, 2013: The multimillennial sea-level commitment of global warming. Proc. Natl. Acad. Sci. USA, 110, 13745-13750, https:// doi.org/10.1073/pnas.1219414110.

Li, C., J.-S. Storch, and J. Marotzke, 2013: Deep-ocean heat uptake and equilibrium climate response. Climate Dyn., 40, 1071-1086, https://doi.org/10.1007 /s00382-012-1350-z.

Luo, Y., J. Lu, F. Liu, and O. Garuba, 2017: The role of ocean dynamical thermostat in delaying the El Niño-like response over the equatorial Pacific to climate warming. J. Climate, 30, 2811-2827, https:// doi.org/10.1175/JCLI-D-16-0454.1.

Lutsko, N. J., and K. Takahashi, 2018: What can the internal variability of CMIP5 models tell us about their climate sensitivity? J. Climate, 31, 5051-5069, https://doi.org/10.1175/JCLI-D-17-0736.1.

Maher, N., D. Matei, S. Milinski, and J. Marotzke, 2018: ENSO change in climate projections: Forced response or internal variability? Geophys. Res. Lett., 45, 11390 11 398, https://doi.org/10.1029/2018GL079764.

—, and Coauthors, 2019: The Max Planck Institute Grand Ensemble: Enabling the exploration of climate system variability. J. Adv. Model. Earth Syst., 11, 2050-2069, https://doi.org/10.1029/2019MS001639.

Manabe, S., R. J. Stouffer, M. J. Spelman, and K. Bryan, 1991: Transient responses of a coupled ocean atmosphere model to gradual changes of atmospheric $\mathrm{CO}_{2}$. Part I. Annual mean response. J. Climate, 4, 785-818, https://doi.org/10.1175/1520-0442(1991)004 $<0785$ :TROACO $>2.0$. CO;2.

Marzocchi, A., and M. F. Jansen, 2017: Connecting Antarctic sea ice to deep-ocean circulation in modern and glacial climate simulations. Geophys. Res. Lett., 44, 6286-6295, https://doi.org/10.1002 /2017GL073936. 
Mauritsen, T., and R. Pincus, 2017: Committed warming inferred from observations. Nat. Climate Change, 7, 652-655, https://doi.org/10.1038/nclimate3357.

— - and Coauthors, 2018: Developments in the MPI-M Earth system model version 1.2 (MPI-ESM 1.2) and its response to increasing $\mathrm{CO}_{2}$. J. Adv. Model. Earth Syst., 11, 998-1038, https://doi.org/10.1029/2018MS001400.

Meehl, G. A., C. Covey, T. Delworth, M. Latif, B. McAvaney, J. F. B. Mitchell, R. J. Stouffer, and K. E. Taylor, 2007: The WCRP CMIP3 multimodel dataset: A new era in climate change research. Bull. Amer. Meteor. Soc., 88, 1383-1394, https://doi.org/10.1175 /BAMS-88-9-1383.

Meraner, K., T. Mauritsen, and A. Voigt, 2013: Robust increase in equilibrium climate sensitivity under global warming. Geophys. Res. Lett., 40, 5944-5948, https://doi.org/10.1002/2013GL058118.

Miller, R. L., and Coauthors, 2014: CMIP5 historical simulations (1850-2012) with GISS ModelE2. J. Adv. Model. Earth Syst., 6, 441-478, https://doi .org/10.1002/2013MS000266.

Nazarenko, L., and Coauthors, 2015: Future climate change under RCP emission scenarios with GISS ModelE2. J. Adv. Model. Earth Syst., 7, 244-267, https://doi.org/10.1002/2014MS000403.

Paynter, D., T. L. Frölicher, L. W. Horowitz, and L. G. Silvers, 2018: Equilibrium climate sensitivity obtained from multimillennial runs of two GFDL climate models. J. Geophys. Res. Atmos., 123, 1921-1941, https://doi.org/10.1002/2017JD027885.

Proistosescu, C., and P. J. Huybers, 2017: Slow climate mode reconciles historical and model-based estimates of climate sensitivity. Sci. $A d v ., 3$, e1602821, https://doi.org/10.1126/sciadv.1602821.

Ramanathan, V., R. D. Cess, E. F. Harrison, P. Minnis, B. R. Barkstrom, E. Ahmad, and D. Hartmann, 1989: Cloud-radiative forcing and climate: Results from the Earth Radiation Budget Experiment. Science, 243, 57-63, https://doi.org/10.1126/science .243.4887.57.

Rehfeld, K., T. Münch, S. L. Ho, and T. Laepple, 2018: Global patterns of declining temperature variability from the Last Glacial Maximum to the Holocene. Nature, 554, 356-359, https://doi.org/10.1038 /nature25454.

Rind, D., G. A. Schmidt, J. Jonas, R. Miller, L. Nazarenko, M. Kelley, and J. Romanski, 2018: Multicentury instability of the Atlantic Meridional circulation in rapid warming simulations with GISS ModelE2. J. Geophys. Res. Atmos., 123, 6331-6355, https://doi .org//10.1029/2017JD027149.

Rodgers, K. B., J. Lin, and T. L. Frölicher, 2015: Emergence of multiple ocean ecosystem drivers in a large ensemble suite with an Earth system model. Biogeosciences, 12, 3301-3320, https://doi.org/10.5194 /bg-12-3301-2015.

Rohrschneider, T., B. Stevens, and T. Mauritsen, 2019: On simple representations of the climate response to external radiative forcing. Climate Dyn., 53, 31313145, https://doi.org/10.1007/s00382-019-04686-4.

Rugenstein, M. A. A., K. Caldeira, and R. Knutti, 2016a: Dependence of global radiative feedbacks on evolving patterns of surface heat fluxes. Geophys. Res. Lett., 43, 9877-9885, https://doi.org/10.1002/2016GL070907.

—, J. M. Gregory, N. Schaller, J. Sedláček, and R. Knutti, 2016b: Multiannual ocean-atmosphere adjustments to radiative forcing. J. Climate, 29, 56435659, https://doi.org/10.1175/JCLI-D-16-0312.1.

—, J. Sedláček, and R. Knutti, 2016c: Nonlinearities in patterns of long-term ocean warming. Geophys. Res. Lett., 43, 3380-3388, https://doi.org/10.1002 /2016GL068041.

— , and Coauthors, 2019: Equilibrium climate sensitivity estimated by equilibrating climate models. Geophys. Res. Lett., https://doi.org/10.1029/2019GL083898, in press.

Saint-Martin, D., and Coauthors, 2019: Fast forward to perturbed equilibrium climate. Geophys. Res. Lett., 46, 8969-8975, https://doi.org/10.1029/2019GL083031.

Salzmann, M., 2017: The polar amplification asymmetry: Role of Antarctic surface height. Earth Syst. Dyn., 8, 323-336, https://doi.org/10.5194/esd-8-323-2017.

Scheff, J., R. Seager, H. Liu, and S. Coats, 2017: Are glacials dry? Consequences for paleoclimatology and for greenhouse warming. J. Climate, 30, 6593-6609, https://doi.org/10.1175/JCLI-D-16-0854.1.

Schmidt, G. A., and Coauthors, 2014: Configuration and assessment of the GISS ModelE2 contributions to the CMIP5 archive. J. Adv. Model. Earth Syst., 6, 141-184, https://doi.org/10.1002/2013MS000265.

Schneider, T., C. M. Kaul, and K. G. Pressel, 2019: Possible climate transitions from breakup of stratocumulus decks under greenhouse warming. Nat. Geosci., 12, 163-167, https://doi.org/10.1038/s41561 -019-0310-1.

Senior, C. A., and J. F. B. Mitchell, 2000: The time-dependence of climate sensitivity. Geophys. Res. Lett., 27, 2685-2688, https://doi.org/10.1029/2000GL011373.

Smith, R. S., J. M. Gregory, and A. Osprey, 2008: A description of the FAMOUS (version XDBUA) climate model and control run. Geosci. Model Dev., 1, 53-68, https://doi.org/10.5194/gmd-1-53-2008.

Sniderman, J. M. K., and Coauthors, 2019: Southern Hemisphere subtropical drying as a transient response to warming. Nat. Climate Change, 9, 232-236, https://doi.org/10.1038/s41558-019-0397-9. 
Song, X., and G. J. Zhang, 2014: Role of climate feedback in El Nino-like SST response to global warming. J. Climate, 27, 7301-7318, https://doi.org/10.1175/JCLI-D $-14-00072.1$

Stouffer, R. J., and S. Manabe, 1999: Response of a coupled ocean-atmosphere model to increasing atmospheric carbon dioxide: Sensitivity to the rate of increase. J. Climate, 12, 2224-2237, https://doi.org/10 .1175/1520-0442(1999)012<2224:ROACOA >2.0.CO;2.

- , and - 2003: Equilibrium response of thermohaline circulation to large changes in atmospheric $\mathrm{CO}_{2}$ concentration. Climate Dyn., 20, 759-773, https://doi.org/10.1007/s00382-002-0302-4.

Svendsen, S. H., M. S. Madsen, Y. Suting, C. Rodehacke, and G. Adalgeirsdottir, 2015: An introduction to the coupled EC-EARTH-PISM model system. Danish Climate Centre Rep. 15-05, 54 pp.

Taylor, K. E., R. J. Stouffer, and G. A. Meehl, 2012: An overview of CMIP5 and the experiment design. Bull. Amer. Meteor. Soc., 93, 485-498, https://doi .org/10.1175/BAMS-D-11-00094.1.

Thomas, M. D., and A. V. Fedorov, 2019: Mechanisms and impacts of a partial AMOC recovery under enhanced freshwater forcing. Geophys. Res. Lett., 46, 3308-3316, https://doi.org/10.1029/2018GL080442.

Trossman, D. S., J. B. Palter, T. M. Merlis, Y. Huang, and Y. Xia, 2016: Large-scale ocean circulation-cloud interactions reduce the pace of transient climate change. Geophys. Res. Lett., 43, 3935-3943, https:// doi.org/10.1002/2016GL067931.

Vial, J., J.-L. Dufresne, and S. Bony, 2013: On the interpretation of inter-model spread in CMIP5 climate sensitivity estimates. Climate Dyn., 41, 3339-3362, https://doi.org/10.1007/s00382-013-1725-9.

Voldoire, A., and Coauthors, 2019: Evaluation of CMIP6 deck experiments with CNRM-CM6-1. J. Adv. Model. Earth Syst., 11, 2177-2213, https://doi.org/10.1029 /2019MS001683.

Voss, R., and U. Mikolajewicz, 2001: Long-term climate changes due to increased $\mathrm{CO}_{2}$ concentration in the coupled atmosphere-ocean general circulation model ECHAM3/LSG. Climate Dyn., 17, 45-60, https://doi .org/10.1007/PL00007925.

Winton, M., K. Takahashi, and I. M. Held, 2010: Importance of ocean heat uptake efficacy to transient climate change. J. Climate, 23, 2333-2344, https://doi .org/10.1175/2009JCLI3139.1.

Yamamoto, A., A. Abe-Ouchi, M. Shigemitsu, A. Oka, K. Takahashi, R. Ohgaito, and Y. Yamanaka, 2015: Global deep ocean oxygenation by enhanced ventilation in the Southern Ocean under long-term global warming. Global Biogeochem. Cycles, 29, 1801-1815, https://doi.org/10.1002/2015GB005181.

Yeager, S. G., C. A. Shields, W. G. Large, and J. J. Hack, 2006: The low-resolution CCSM3. J. Climate, 19, 2545-2566, https://doi.org/10.1175/JCLI3744.1.

Yoshimori, M., M. Watanabe, H. Shiogama, A. Oka, A. Abe-Ouchi, R. Ohgaito, and Y. Kamae, 2016: A review of progress towards understanding the transient global mean surface temperature response to radiative perturbation. Prog. Earth Planet. Sci., 3, 21, https://doi.org/10.1186/s40645-016-0096-3.

Zhang, X., G. Lohmann, G. Knorr, and X. Xu, 2013: Different ocean states and transient characteristics in Last Glacial Maximum simulations and implications for deglaciation. Climate Past, 9, 2319-2333, https:// doi.org/10.5194/cp-9-2319-2013.

Zhou, C., M. D. Zelinka, and S. A. Klein, 2016: Impact of decadal cloud variations on the Earth's energy budget. Nat. Geosci., 9, 871-874, https://doi .org/10.1038/ngeo2828.

Zhu, J., Z. Liu, J.Zhang, and W. Liu, 2015: AMOC response to global warming: Dependence on the background climate and response timescale. Climate Dyn., 44, 3449-3468, https://doi.org/10.1007/s00382-014-2165-x.

Zickfeld, K., and Coauthors, 2013: Long-term climate change commitment and reversibility: An EMIC intercomparison. J. Climate, 26, 5782-5809, https:// doi.org/10.1175/JCLI-D-12-00584.1. 


\section{AMS Members}

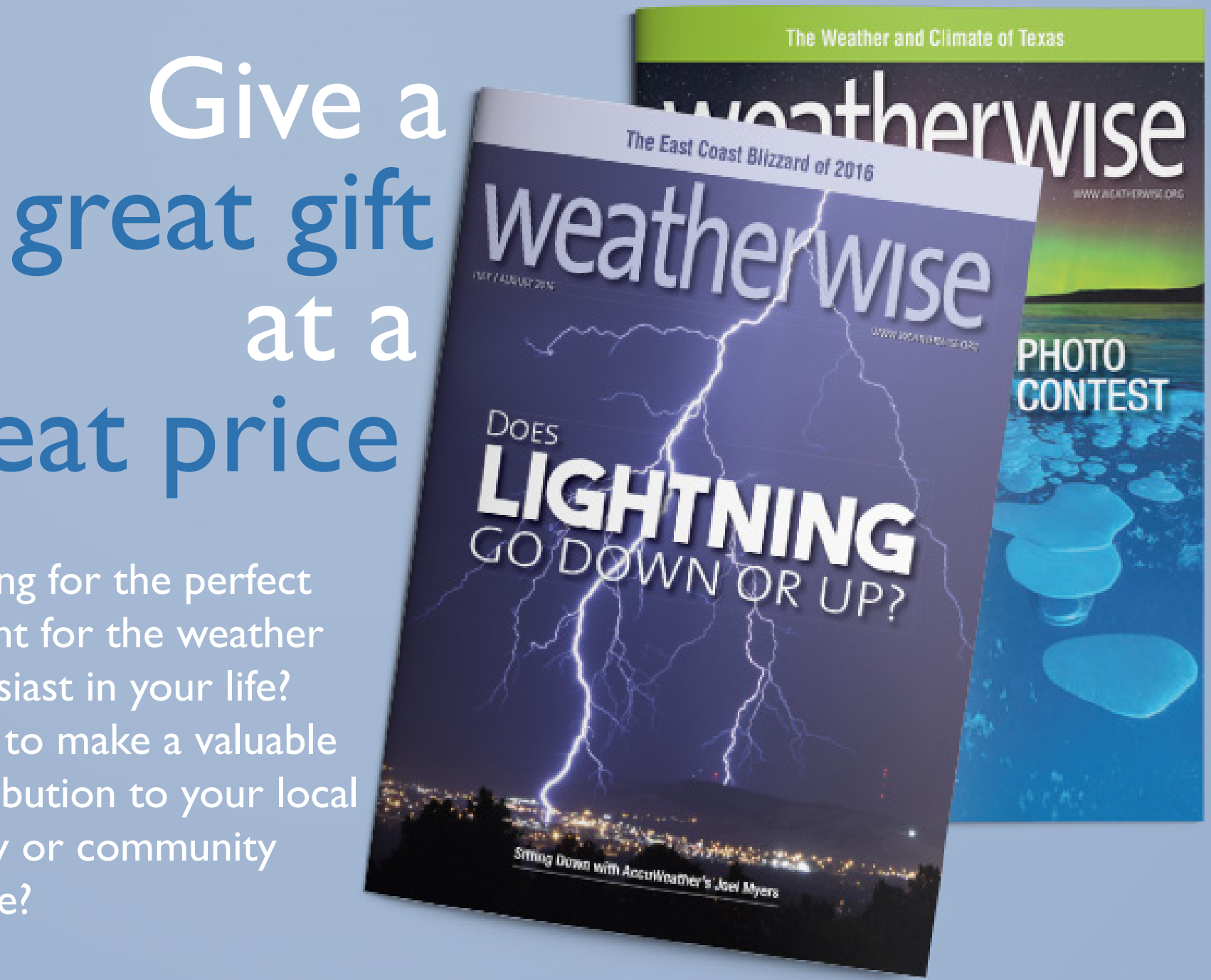

Send a subscription to Weatherwise magazine for just $\$ 24.95 *$-That's nearly $50 \%$ off the list price!

Contact Member Services by e-mail at amsmem@ametsoc.org or

by phone at 617-227-2425 to place all of your Weatherwise orders today!
Written for a general audience, Weatherwise offers a colorful and nontechnical look at recent discoveries in meteorology and climatology.

Check out the latest table of contents at www.weatherwise.org.

\section{Want your own?}

Then order a personal subscription at the same great price. 